\title{
“Consideraciones sobre la Conducción de la Política Monetaria y el Mecanismo de Transmisión en México"
}

\author{
Lorenza Martínez \\ Oscar Sánchez \\ Alejandro Werner \\ Marzo de 2001 \\ Documento de Investigación No. 2001-02 \\ Dirección General de Investigación Económica \\ BANCO DE MÉXICO
}

Los autores agradecen los comentarios de Armando Baqueiro, Miguel Messmacher, Klaus SchmidtHebbel e Ignacio Trigueros y la colaboración de José Antonio Ardavín, Judith Frías y Sandra L. Orozco. Las opiniones contenidas en este documento corresponden exclusivamente a los autores y no representan el punto de vista del Banco de México. 


\title{
“Consideraciones sobre la Conducción de la Política Monetaria y el Mecanismo de Transmisión en México"
}

\author{
Lorenza Martínez \\ Oscar Sánchez \\ Alejandro Werner
}

Marzo de 2001

Documento de Investigación No. 2001-02

\begin{abstract}
$\underline{\text { Resumen }}$
En este trabajo se describe la evolución que ha experimentado el esquema de política monetaria en México de 1995 a la fecha, pasando de uno sustentado en objetivos cuantitativos de crecimiento de los agregados monetarios a otro en el cual las acciones discrecionales de política monetaria, con el fin de alcanzar los objetivos de inflación, cobraron mayor relevancia. Además se analizan dos temas que han generado dudas sobre la instrumentación de la política monetaria: el uso del objetivo de saldos acumulados y la efectividad de éste para afectar la inflación por canales alternativos al del tipo de cambio. Los resultados principales indican que el comportamiento de la tasa de interés real ha sido determinado por las variables tradicionales que guían las acciones discrecionales de cualquier Banco Central y que dichas tasas han afectado de manera estadísticamente significativa a la demanda agregada y al crédito.
\end{abstract}




\section{“Consideraciones sobre la Conducción de la Política Monetaria y el Mecanismo de Transmisión en México"}

\section{Introducción}

A partir de la adopción del régimen de libre flotación como consecuencia de la crisis de balanza de pagos de 1994-1995, la política monetaria ha asumido el papel del ancla nominal de la economía. En 1995, existían pocas experiencias de países con características económicas similares a las de México que tuvieran un régimen de flotación cambiaria. Así, el esquema actual de política monetaria ha sido el resultado de un proceso evolutivo, el cual se ha visto influido por las experiencias de economías desarrolladas pequeñas que cuentan con un régimen de flotación y, posteriormente, por lo sucedido en otras economías latinoamericanas que han adoptado regímenes cambiarios flexibles.

En la sección II de este trabajo se describe esta evolución del esquema de política monetaria, partiendo de uno basado en el análisis de los agregados monetarios a otro en el cual las acciones discrecionales de política monetaria, con el objeto de alcanzar los objetivos de inflación propuestos, cobraron mayor relevancia. En esta sección se examina la evolución de la base monetaria durante el período posterior a la crisis y se argumenta que la inestabilidad que ha mostrado la relación entre la base monetaria y los precios, limitó severamente el uso de dicha variable como indicadores de presiones inflacionarias.

En las secciones III y IV, el trabajo se enfoca al estudio de dos temas que han generado dudas sobre la instrumentación de la política monetaria en México: el uso del objetivo de saldos acumulados y la efectividad de éste para afectar la inflación por canales alternativos al del tipo de cambio. En ambos casos se encuentra que el esquema actual de política monetaria sí es efectivo. Esta conclusión se sustenta en el hecho de que el comportamiento de las tasas reales de interés puede explicarse con las variables tradicionales que guían las acciones discrecionales de política monetaria de cualquier Banco Central, entre las que destacan la diferencia entre la inflación esperada y el objetivo de inflación, los excesos de demanda agregada y las perturbaciones financieras externas. En segundo lugar, se demuestra que los aumentos de la tasa real de interés han influido sobre la demanda agregada, el crédito no bancario y la inflación. Finalmente, en la sección $\mathrm{V}$ se presentan las principales conclusiones del trabajo. 


\section{Evolución del Esquema de Política Monetaria en México: 1995-2000}

La crisis cambiaria y financiera que tuvo lugar a finales de 1994 y durante 1995 obligó a las autoridades a adoptar un régimen cambiario de libre flotación. Por tanto, se abandonó el uso del tipo de cambio como el ancla nominal de la economía. Como consecuencia de la devaluación del peso y del repunte de la inflación, la credibilidad del Banco de México se vio severamente dañada. Las críticas se concentraron en la falta de transparencia en la conducción de la política monetaria, en la limitada diseminación de información y en la falta de determinación para restringir la política monetaria antes, durante e inmediatamente después de la crisis.

Debido a estas críticas, y a la necesidad de establecer un ancla nominal visible y estricta, en 1995 se adoptó un límite al crecimiento del crédito interno neto del Banco Central durante dicho año. Este límite se derivó de la estimación del crecimiento de la demanda de base monetaria y de una nula acumulación anticipada de reservas internacionales. Conviene aclarar que en ese entonces no se pensó que dicho limite o en el crecimiento de la base, constituyeran objetivos intermedios que podrían ser utilizados como reglas cuasiautomáticas, por lo que sus limitaciones eran conocidas por la autoridad. Sin embargo, debido a la crisis de credibilidad por la que atravesaba el Instituto Central, se juzgó conveniente la adopción de un objetivo monetario muy visible. Las limitaciones de los agregados monetarios y sus ventajas en las circunstancias en las que se encontraba la economía mexicana se expresaron de la siguiente manera en el programa monetario para $1995^{1}$ :

La mayoría de los bancos centrales ha dejado de adoptar objetivos cuantitativos en cuanto a la evolución de su propio crédito o de agregados monetarios tales como los billetes y monedas en circulación, medio circulante u otros. Esto, debido a que los cambios tecnológicos o de regulación financiera, ocurridos en las últimas décadas, han dado lugar a que se haya perdido en buena medida la relación más o menos estable, que años atrás existía, entre alguno de esos agregados y el PIB nominal.

No obstante lo expresado en el párrafo inmediato anterior, la presente crisis de confianza en la moneda nacional determina la conveniencia de que el Banco Central adopte una política de crédito primario sumamente estricta. Esto lo puede hacer imponiéndose un límite al crecimiento de su crédito interno durante el año.

Esta fórmula puede coadyuvar eficazmente a que las expectativas inflacionarias de los agentes económicos vayan convergiendo con las proyecciones de precios contenidas

1 Exposición sobre la Política Monetaria para el lapso $1^{\text {o }}$ de enero de 1995 - 31 de enero de 1995, pp. 53-54. 
en el programa económico adoptado por el Gobierno Federal, las cuales concuerdan con las estipulaciones del Acuerdo de Unidad para Superar la Emergencia Económica.

Además, a consecuencia de la gran incertidumbre respecto de la evolución de la economía mexicana, en ese momento se consideró extremadamente riesgoso utilizar como instrumento de política monetaria la fijación de una tasa de interés de corto plazo. Por tanto, con el fin de aplicar un esquema operativo bajo el cual tanto el tipo de cambio como las tasas de interés fuesen determinadas libremente, el Banco de México estableció el "encaje promedio cero" y la utilización del objetivo de saldos acumulados como instrumento de política monetaria ${ }^{2}$. Mediante el anuncio de dicho objetivo el Banco de México envía señales a los mercados financieros, sin determinar con ello niveles de la tasa de interés o del tipo de cambio.

Bajo este esquema, el Banco de México interviene todos los días en el mercado de dinero mediante subastas, ofreciendo créditos, depósitos, o a través de la compraventa de valores gubernamentales en directo o en reporto. A ese fin, el Banco Central fija el monto a subastar, de manera que la suma de los saldos acumulados de las cuentas corrientes de toda la banca (saldo acumulado de saldos diarios totales) inicie la siguiente jornada en una cantidad determinada de antemano.

Con el fin de enviar señales sobre sus intenciones de política monetaria, el Banco de México da a conocer la cantidad a la que pretende llevar el "saldo acumulado de los saldos diarios totales" (SA) de las cuentas corrientes de la banca a la apertura del siguiente día hábil. De esta manera, por ejemplo, un objetivo de SA igual a cero subraya la intención del Banco Central de satisfacer, a tasas de interés de mercado, la demanda de billetes y, por tanto, de proporcionar los recursos necesarios para que ningún banco se vea obligado a incurrir en sobregiros o a acumular saldos positivos no deseados al finalizar el periodo de cómputo. Esto sería indicativo de una política monetaria neutral.

Un objetivo de SA negativo, "un corto", señalaría la intención del Banco Central de no proporcionar a la banca los recursos suficientes a tasas de interés de mercado, obligando así a una o varias instituciones de crédito a obtener una parte de los recursos requeridos a través del sobregiro en sus cuentas corrientes. Esto último, haciendo abstracción de otras influencias, puede provocar un alza en las tasas de interés, ya que las instituciones tratarán de evitar pagar la elevada tasa aplicable 
al sobregiro, buscando obtener esos recursos en el mercado de dinero. Esta circunstancia le estaría enviando la señal al mercado de que el Banco de México ha adoptado una postura restrictiva de política monetaria.

De esta explicación se infiere que el Banco de México siempre proporciona el crédito suficiente para atender plenamente la demanda de billetes y monedas, incluso cuando adopta un objetivo de saldo acumulado negativo. Sólo que en este último caso, parte de ese crédito es otorgado a una tasa de castigo, mediante un sobregiro en la cuenta corriente de uno o más bancos.

En 1995, al igual que en los años precedentes, el Banco de México determinó un objetivo para la inflación anual (diciembre 1994-diciembre 1995), el cual, después de las modificaciones realizadas al programa económico durante el primer trimestre del año, se fijó en 42 por ciento.

Además, en ese año el Banco de México impulsó el desarrollo de los mercados de futuros y opciones del peso mexicano y se estableció una nueva política de información. Ello, con el fin de que los agentes económicos contaran con los instrumentos financieros para protegerse de la mayor volatilidad cambiaria y con la información necesaria para dar mejor seguimiento a las acciones de la autoridad monetaria.

En los dos años siguientes, 1996 y 1997, se mantuvo el esquema de política monetaria descrito, enfatizándose los límites sobre el crecimiento del crédito interno neto y el pronóstico de incremento de la base monetaria. En 1996, los límites al aumento del crédito interno neto, el objetivo de acumulación de activos internacionales y el pronóstico de crecimiento de la base monetaria se presentaron de manera trimestral. Asimismo, en 1997 en el programa monetario se hizo pública la trayectoria diaria de la demanda de base monetaria durante el año.

La acusada estacionalidad que exhibe la demanda de base monetaria generó la percepción de que en algunos periodos del año la política monetaria era muy expansiva. Por ese motivo, en los programas monetarios se decidió anunciar el pronóstico trimestral y diario. Al hacerlo se muestra que estos aumentos estacionales son congruentes con el pronóstico anual y no representan una postura más laxa de política monetaria, por lo que se evitan las confusiones asociadas a los aumentos estacionales de la base monetaria. Sin embargo, al acortarse los plazos de estos compromisos aumentaba la posibilidad de incumplirlos, debido a fenómenos transitorios o fortuitos, ya que la inestabilidad de la relación entre dinero y precios es más marcada en periodos de corta

2 Para una explicación detallada de este mecanismo véase el Informe Anual del Banco de México de 1997, Anexo 4. 
duración. En 1996 y 1997, las metas de inflación fijadas por el Banco de México fueron de 20.5 y 15 por ciento, respectivamente.

En relación con las acciones discrecionales del Banco de México, durante estos años la aplicación del "corto" se orientó a restaurar las condiciones de estabilidad en los mercados financieros cuando éstos sufrían alguna perturbación. Una vez que se lograba lo anterior, el objetivo de saldos acumulados regresaba a cero. En este sentido, el objetivo de inflación anual jugaba un papel importante para guiar las expectativas de los agentes económicos y las acciones discrecionales de política monetaria instrumentadas durante el año se orientaban a minimizar el impacto de perturbaciones financieras no anticipadas sobre la trayectoria de la inflación.

La inflación se redujo de 52 por ciento en 1995 a 15.7 por ciento en 1997. Sin embargo, como se presenta en la Gráfica 1, debido a la gran incertidumbre inflacionaria asociada a los elevados niveles de inflación, los objetivos anuales de 1995 y 1996 no fueron alcanzados, aunque en 1997 la inflación fue tan sólo 0.7 puntos porcentuales (p.p.) superior a la meta propuesta.

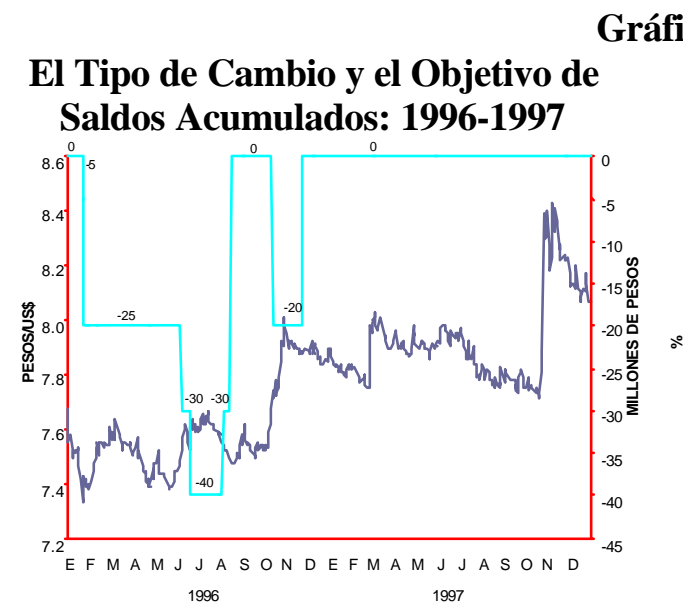

\section{Gráfica 1} Inflación y Objetivo de Inflación en México: 1995-1997

A partir de 1998, el esquema de política monetaria comenzó una transición gradual hacia un esquema de objetivos explícitos de inflación. En consecuencia, se ha ido restando énfasis al comportamiento de la base monetaria en el análisis de las presiones inflacionarias, aumentándose la importancia de las metas de inflación de corto y mediano plazos. A la vez, la instrumentación de las acciones discrecionales de política monetaria se orientaron fundamentalmente a la consecución de los objetivos de inflación de corto y mediano plazo.

Si bien el Programa Monetario para 1998 fue similar al del año precedente, se detectaron algunos cambios que sugieren el inicio de la transición aludida en el párrafo anterior. En particular, en dicho documento se hace una descripción más detallada de cual sería la reacción de la autoridad 
monetaria ante la materialización de diferentes perturbaciones externas e internas. Otro elemento indicativo de esta transición fue el incremento en el "corto" en noviembre de ese año, cuando a raíz de la crisis rusa y de la caída del precio del petróleo la inflación se desvió de la meta propuesta. El propósito de esta reacción del Banco de México fue:

Procurar, a través del manejo de la política monetaria, una pronta inflexión en la tendencia reciente de la inflación anual. Por ello [la Junta de Gobierno] ha decidido emprender desde ahora acciones en materia monetaria, de tal forma que podamos alcanzar el objetivo de inflación de 13 por ciento establecido para diciembre de 1999. Así, con el objeto de contrarrestar el proceso de revisión al alza de las expectativas inflacionarias para 1999, de evitar reacciones desordenadas de precios y de estar en posibilidad de alcanzar la meta de inflación de 13 por ciento para el próximo año, la Junta de Gobierno del Banco de México ha decidido acentuar la restricción monetaria, aumentando el monto del "corto" de 100 millones a 130 millones de pesos.

Ésta fue la primera ocasión en que el "corto" se incrementaba explícitamente con un criterio preventivo, con el fin de inducir las condiciones monetarias apropiadas que llevaran a la consecución del objetivo de inflación del año siguiente.

En el Programa Monetario para 1999 se fijó como objetivo una inflación que no excediera de 13 por ciento y también se propuso como meta del esfuerzo estabilizador para el siguiente quinquenio una aproximación gradual a la inflación externa. Este objetivo de largo plazo se fue haciendo más explícito y, actualmente, la meta de largo plazo de la política monetaria es alcanzar en el año 2003 una inflación de 3 por ciento. A su vez, la conducción de la política monetaria continuó transitando hacia un manejo preventivo en el cual se reconocen los rezagos con los que ésta incide sobre la evolución de los precios y, por ende, la necesidad de actuar con anticipación para inducir un comportamiento congruente con las metas propuestas. Asimismo, para 2000 se estableció como meta una inflación menor que 10 por ciento y en octubre de ese mismo año se anunciaron los objetivos de inflación para los años 2001 (6.5 por ciento) y 2003 (3 por ciento), y se proporcionó una indicación respecto a la meta que se adoptaría para el año 2002 (4.5 por ciento).

Durante el periodo 1998-2000 también se continuó reduciendo la importancia asignada al crecimiento de los agregados monetarios en el análisis de las próximas inflaciones. Si bien las

3 Banco de México, Boletín de Prensa No. 139, noviembre 30, 1998. 
estimaciones realizadas para la demanda por base monetaria indican la existencia de una función estable en el largo plazo, la inestabilidad de corto plazo hace desaconsejable su utilización como objetivo intermedio. Estudios recientes (Garcés (2000)) han identificado una demanda de base monetaria de largo plazo estable para el período 1982-2000. Además, las elasticidades de largo plazo estimadas son consistentes con una demanda de dinero de la forma Baumol-Tobin. Sin embargo, las desviaciones con respecto a esta demanda de base monetaria de largo plazo que se presentan en el corto plazo son elevadas (de cerca de 7.9 por ciento) y se eliminan en un periodo prolongado (50 por ciento en cuatro trimestres y 95 por ciento en dieciseis trimestres). Por tanto, si bien en un horizonte largo esta relación se mantiene, en periodo anuales se presentan desviaciones importantes. En la Gráfica 2 se ilustra la relación entre el crecimiento de la base monetaria y la inflación en el período 1995-1999.

\section{Gráfica 2}

\section{Crecimiento Nominal Anual de la Base Monetaria} e Inflación: 1995-1999

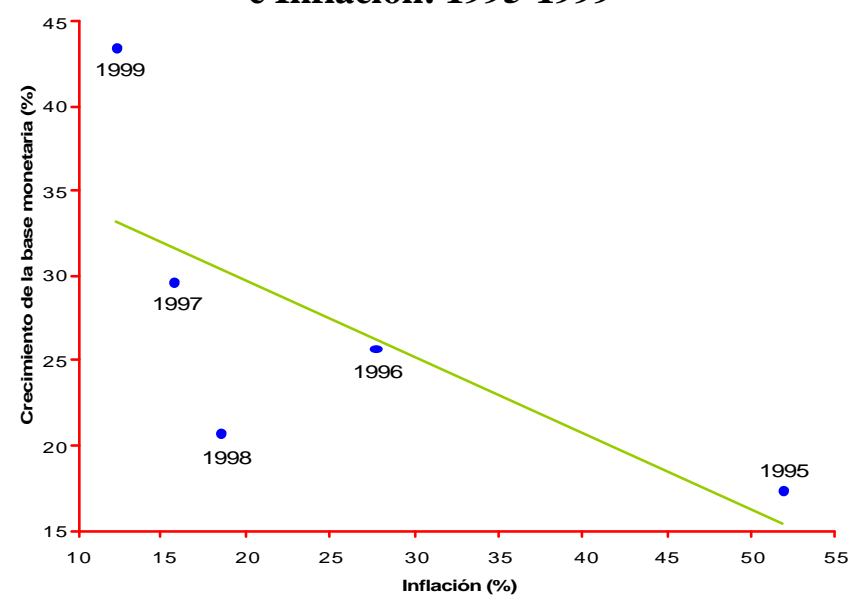

En el Cuadro 1 se muestra como en aquellos años en los que se ha alcanzado el objetivo de inflación, la base monetaria se ha desviado de su meta, mientras que en los años en los que la inflación superó la meta, el crecimiento de la base monetaria resultó similar al pronosticado. Además, en este cuadro se hace patente que para la formación de las expectativas inflacionarias, los agentes económicos incorporan el cumplimiento pasado de las metas de inflación y no el que se hayan alcanzado los objetivos de crecimiento de la base monetaria. 


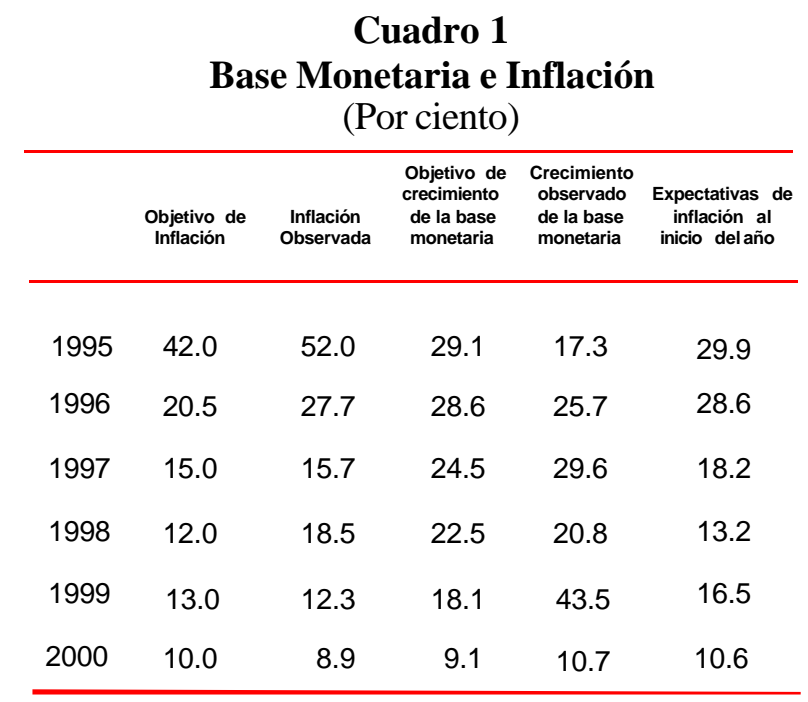

Debido a la significativa brecha entre el crecimiento observado y el anticipado de la base monetaria en 1999, en el Programa Monetario del año 2000 se explicaron con detalle las razones por las cuales se reducía la importancia de dichos elementos en el esquema de política monetaria. Profundizando respecto a este último punto, cabe destacar que durante 1999 continuó el proceso de remonetización iniciado en 1997, una vez que la inflación retomó una clara tendencia descendente. En este sentido, como se aprecia en la Gráfica 3, la proporción de billetes y monedas a PIB registrada en 1998 y en 1999 resultó menor que la observada en 1991 y 1992, cuando se registraron niveles similares de inflación. En la gráfica se muestra la relación entre la tasa de inflación anual y el cociente de billetes y monedas a PIB para el período 1994-1999. Se puede apreciar que el proceso de remonetización sólo comienza una vez que el descenso de la tasa de inflación se ha consolidado. Además, en dicha gráfica se hace patente que los episodios de desmonetización son significativamente más rápidos que los de remonetización. Por tanto, en la medida en que se consolide el proceso desinflacionario sería razonable esperar que dicho cociente continuara creciendo.

\section{Gráfica 3}

Saldo de la Base Monetaria como Porcentaje del PIB e Inflación Anual

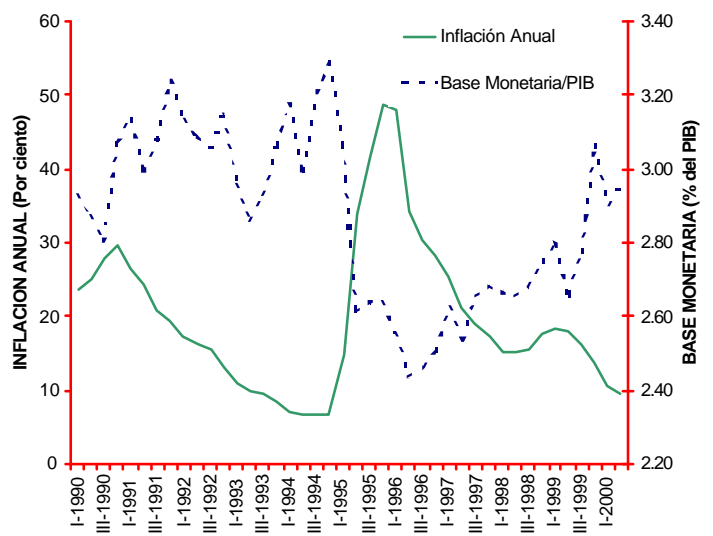


De haberse generado deliberadamente un sobrante de oferta de base monetaria, éste se hubiese reflejado en el comportamiento de los mercados financieros. En particular, los agentes económicos hubiesen deseado deshacerse del exceso de billetes y monedas adquiriendo activos denominados en moneda extranjera, causando así una depreciación del tipo de cambio. Como se aprecia en la Gráfica 4, la brecha entre la evolución observada de la base monetaria y la programada que se presentó en 1999 y en algunos meses de 2000 difícilmente puede asociarse con depreciaciones del tipo de cambio.

\section{Gráfica 4}

Desviación de la Base Monetaria y el Tipo de Cambio

1999

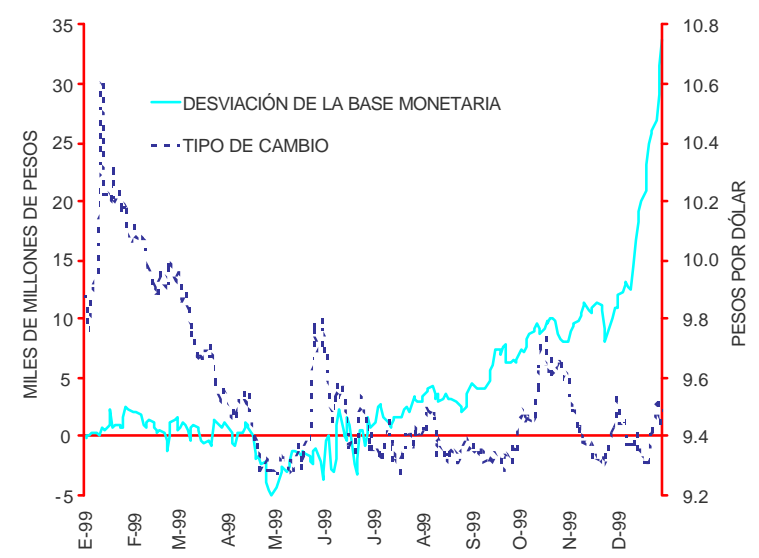

2000

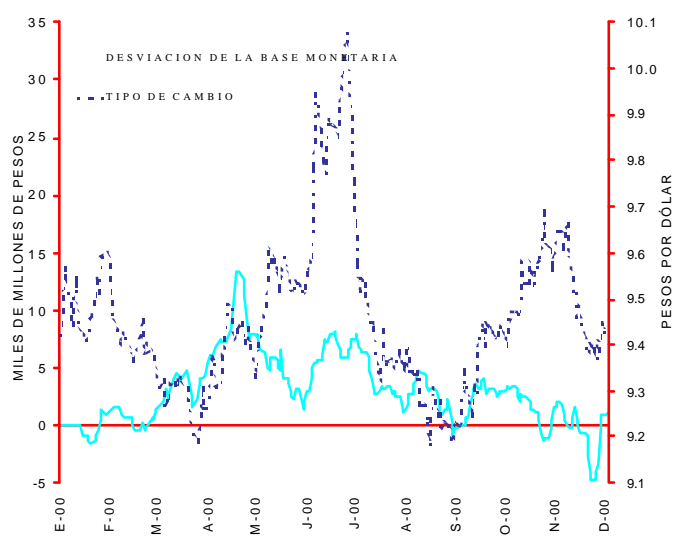

La ausencia de una relación estable entre los agregados monetarios y la inflación ha llevado a la gran mayoría de los bancos centrales del mundo a reducir la importancia otorgada a la evolución de dichos agregados en el análisis y evaluación de las presiones inflacionarias. Por tanto, el hecho descrito ha desacreditado la utilización mecánica de estas variables para la conducción de la política monetaria. Varios autores, por ejemplo Mishkin (2000), han descrito con detalle la experiencia internacional referente al uso de agregados monetarios como objetivos intermedios. La evidencia que sustenta la decisión de diversos bancos centrales de reducir la importancia de la evolución de los agregados monetarios en el análisis de las presiones inflacionarias se presenta en la Gráfica 5, donde se muestran las tasas de crecimiento de la base monetaria y del nivel general de precios para un conjunto de países desarrollados. En dicha gráfica puede apreciarse qué la relación comentada no ha sido estable - sobre todo en el corto plazo - y que en varias ocasiones se ha detectado que en aquellos períodos en los que la inflación disminuye, la tasa de crecimiento de la base monetaria aumenta de manera considerable. 


\section{Gráfica 5}

Tasa de Crecimiento de los Billetes y Monedas en

Circulación e Inflación: Experiencia Internacional
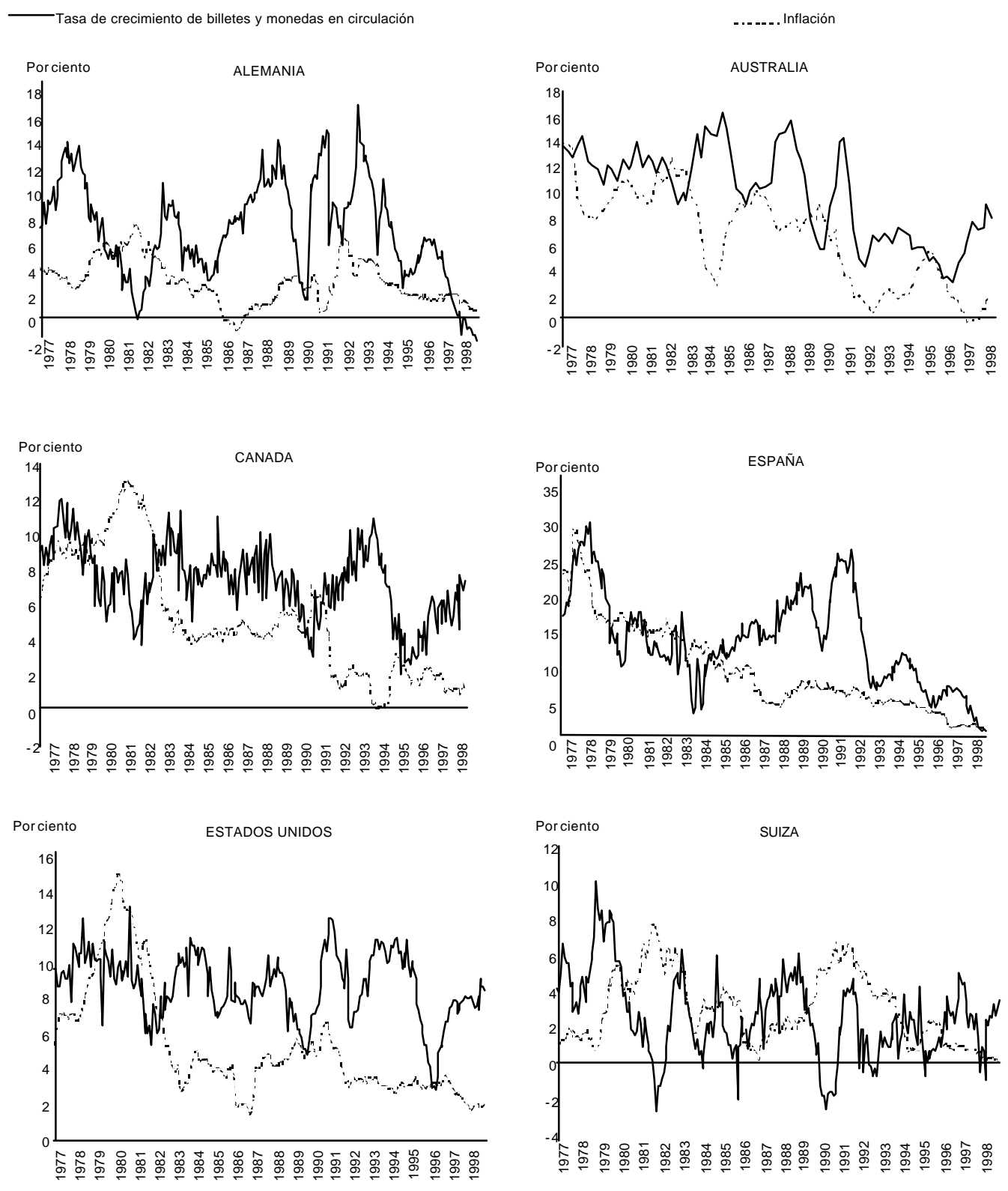

Fuente: Estadísticas Financieras Internacionales, FMI

En suma, la experiencia internacional y la nacional indican que el fenómeno inflacionario es de tal complejidad que no puede ser anticipado con exactitud por el comportamiento de tan sólo unas cuantas variables. 
En consecuencia, en la actualidad el Banco de México ajusta su postura de política monetaria cuando se presenta la necesidad de modificar las condiciones monetarias en la economía para que éstas sean congruentes con el logro de las metas de inflación. En particular, el Instituto Central utilizará los “cortos”, adoptando así una política monetaria más restrictiva, principalmente en las siguientes circunstancias:

1. Cuando detecte presiones inflacionarias futuras incongruentes con el logro de los objetivos de inflación adoptados y, por ende, las expectativas inflacionarias se desvíen considerablemente respecto de las metas de inflación;

2. Cuando se presenten perturbaciones inflacionarias. En particular, la política monetaria procurará en toda circunstancia neutralizar los efectos secundarios de las perturbaciones exógenas sobre los precios y, en ocasiones, actuará de manera precautoria para contrarrestar parcialmente los efectos inflacionarios directos que originen los movimientos de los precios clave en la economía. El objetivo final es que los ajustes necesarios de los precios relativos afecten sólo moderadamente al INPC, elevando su nivel pero evitando el deterioro de las expectativas inflacionarias;

3. Cuando se necesite restaurar condiciones ordenadas en los mercados cambiarios y de dinero.

Al no existir una relación clara en el corto plazo entre el crecimiento de la base monetaria y las presiones inflacionarias, hasta 1999 los agentes económicos contaban con pocos elementos de juicio para evaluar la conducción de la política monetaria. Por tanto, en el año 2000, el Banco de México consideró conveniente ampliar los mecanismos de comunicación con el público mediante la publicación de informes trimestrales sobre la inflación. En dichos informes se describe y analiza la evolución de la inflación, la aplicación de la política monetaria y se presenta un balance de riesgos sobre la evolución futura del crecimiento de los precios.

La introducción de un objetivo de inflación de mediano plazo, la ampliación de los mecanismos de comunicación con el público, la menor utilidad de los agregados monetarios y el propio descenso de la inflación, llevaron a un cambio importante en la aplicación de la política monetaria en México.

En la actualidad, las acciones de política monetaria se han orientado a influir sobre las condiciones monetarias y las expectativas de inflación para alcanzar la congruencia entre éstas y los 
objetivos propuestos. Así, durante gran parte del período 1998-2000, al ser las expectativas de inflación del público superiores a los objetivos propuestos, la autoridad ha tenido que intensificar la postura restrictiva de política monetaria. En el lapso 1998-2000, las modificaciones de la política monetaria hacia una mayor restricción (aumentos del "corto") han tenido una mayor permanencia (Gráfica 6). Esto contrasta con lo observado en 1996-1997, cuando ante una brecha entre las expectativas y los objetivos, el "corto" se utilizó principalmente para calmar a los mercados, por lo que sus ampliaciones tuvieron un carácter transitorio.

Si bien en 1998, debido a las perturbaciones externas que enfrentó la economía mexicana y a los aumentos no programados de los precios de los bienes administrados y concertados por el sector público, la inflación se desvió de su objetivo, en 1999 y 2000 ésta resultó menor que las metas originalmente establecidas (Gráfica 6).

\section{Gráfica 6}

Tipo de Cambio y Objetivo de Saldos

Acumulados: 1998-2000

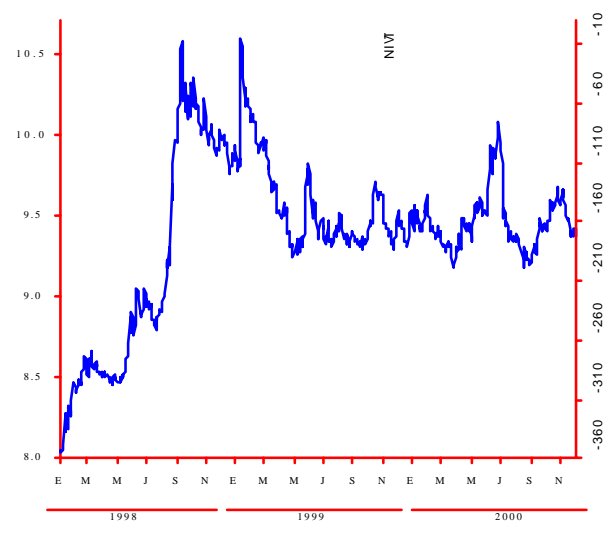

Inflación y Objetivo de Inflación

1998-2000

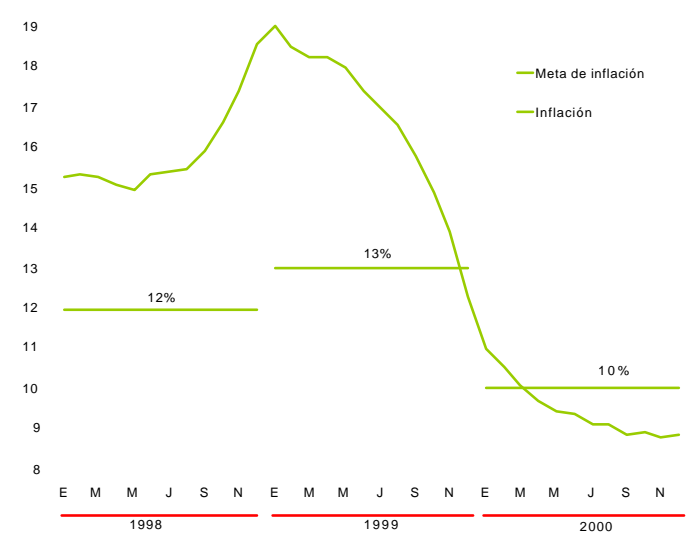

Para ilustrar de manera clara el cambio en la función de reacción de la autoridad monetaria, es ilustrativo comparar las acciones de política monetaria y la evolución de las tasas de interés en 1997 y 2000. En estos dos años la economía mexicana se benefició de un entorno externo favorable, la inflación fue similar al objetivo propuesto en ambos años y el incremento real del PIB superó los pronósticos originales (el crecimiento observado fue de 7 por ciento y el anticipado de 4.5 por ciento en ambos años).

Asimismo, en la segunda mitad de estos dos años, la evolución de las expectativas de inflación y de las negociaciones salariales contractuales resultaban incongruentes con los objetivos propuestos para el siguiente año, tal como lo ilustra la Gráfica 7. 
Gráfica 7

\section{Expectativas de Inflación, Salarios Contractuales y}

Objetivo de Inflación del Año Siguiente

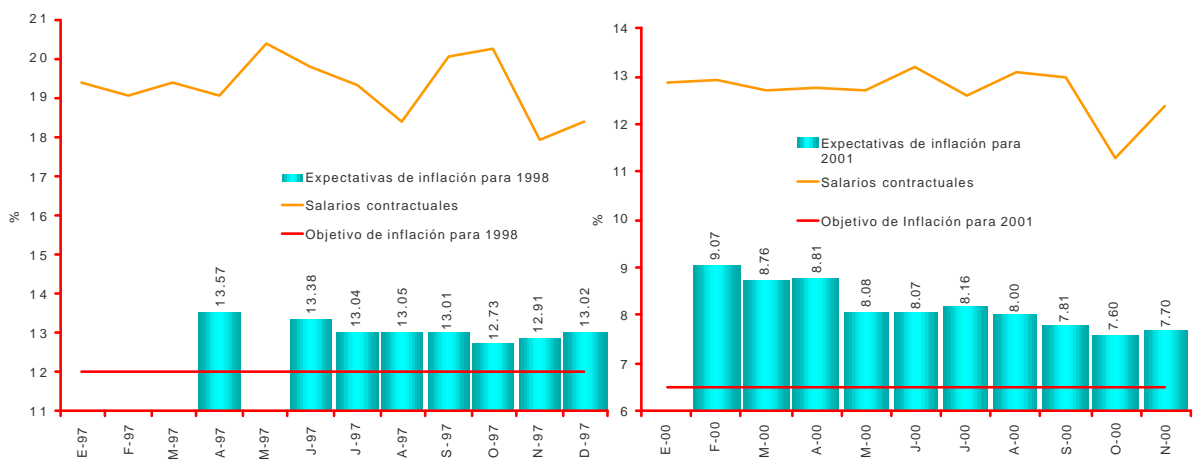

Ante este escenario la autoridad monetaria no respondió preventivamente durante 1997. En contraste, durante 2000, dada la generación de presiones inflacionarias que hubieran obstaculizado el descenso futuro de la inflación, la autoridad monetaria aumentó progresivamente el "corto". Esta diferencia en la reacción de la autoridad se observa claramente en la evolución del diferencial entre la tasa real en pesos de los Cetes a 28 días y el rendimiento bruto del bono UMS26 ${ }^{4}$. Como se observa en la Gráfica 8, este diferencial, en promedio, fue mayor (menos negativo) durante 2000 que en 1997 y, además, aumentó en la segunda mitad del año como respuesta a las acciones restrictivas de política monetaria. Mientras que en 1997 este diferencial fue reduciéndose (haciéndose más negativo) en el transcurso del año y solamente se amplió en respuesta al contagio de la intensificación de la crisis asiática al ser atacadas las monedas de Hong-Kong y Corea. Una vez que se debilitó esta presión, las tasas de interés retomaron su tendencia descendente. Este cambio en la función de reacción de la autoridad se demostrará formalmente más adelante.

\section{Cetes Reales a 28 Días - Rendimiento Bruto UMS 26 1997 2000}

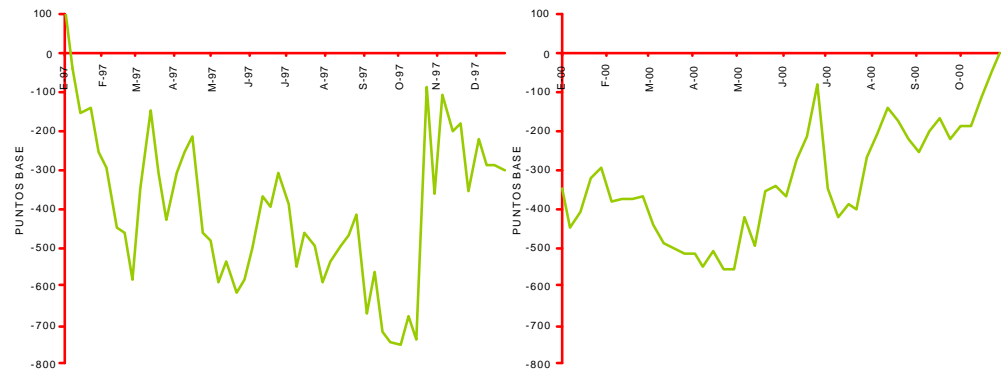

4 Debido a la gran influencia de las tasas ext ernas sobre las internas, este diferencial mide el movimiento de las tasas en moneda nacional una vez que se elimina el efecto que sobre ellas ejercen las tasas externas. 
En la actual transición hacia objetivos explícitos de inflación frecuentemente se ha cuestionado la efectividad de la política monetaria en México. En particular, se han presentado varias discusiones sobre la instrumentación de la política monetaria y sobre los mecanismos de transmisión de la misma. Estos temas se abordan en las siguientes secciones.

\section{La Instrumentación de la Política Monetaria en México}

Hoy en día, la mayoría de los bancos centrales reconoce como meta prioritaria de política la estabilización del nivel de precios. A lo largo de su historia estas instituciones han utilizado como instrumento de política diferentes variables que se encuentran bajo su control:

1. Intervenciones en el mercado de dinero para mantener un nivel de tasa de interés;

2. Manejo de las condiciones de mercado a través de restricciones cuantitativas.

La operación de la política monetaria consiste en definir el nivel del instrumento que, dado el mecanismo de transmisión de la política monetaria, es congruente con la consecución de la meta. No es difícil reconocer que a través de cualquiera de los instrumentos arriba enumerados un Banco Central es capaz de influir, directa o indirectamente, sobre la determinación de la tasa de interés de corto plazo.

Los instrumentos de política monetaria que utilizan los bancos centrales modernos pueden ser clasificados en dos grupos:

1. Intervención en el mercado de dinero para mantener un nivel específico de la tasa de "fondeo" o para limitar su fluctuación dentro de una banda.

2. Manejo de las condiciones del mercado de dinero a través de restricciones cuantitativas.

Por ejemplo, el Sistema de la Reserva Federal de los Estados Unidos (Fed) y el Banco de Inglaterra operan con mecanismos orientados a mantener una tasa de interés objetivo alrededor de un valor puntual. Otros bancos centrales, como el Banco Central Europeo y el Banco de Canadá, ubican a la tasa oficial dentro de un "corredor". Este último se define en términos de una tasa de castigo, a la que el Banco Central ofrece al mercado "fondeo" diario y un piso definido por la tasa que se paga sobre los depósitos que mantienen los bancos comerciales en el Banco Central. 
Como se observa en el Cuadro 2, hoy en día en muchos países la instrumentación de la política monetaria se lleva a cabo a través de la fijación de un objetivo para la tasa de interés de corto plazo. En el pasado, sin embargo, algunos bancos centrales han operado por medio de ajustes, no a una tasa objetivo, sino a la cantidad de fondos prestables en el sistema. Este fue el caso del régimen de objetivos sobre "non-Borrowed Reserves" utilizado por el Fed durante principios de los años ochenta, y el régimen denominado de "Settlement Balances" aplicado en Nueva Zelanda hasta marzo de 1999.

\section{Cuadro 2}

Tasas de Interés Utilizadas para las Acciones de Política Monetaria

\begin{tabular}{|c|c|c|}
\hline País & Tasa de interés utilizada & Plazo \\
\hline Estados Unidos de América & Tasa de "fondeo" federal & 1 día \\
\hline Canadá & Tasa hancaria & 1día \\
\hline Australia & Tasa de efectivo & 1 día \\
\hline Nueva Zelanda & Tasa oficial de efectivo & 1 día \\
\hline Inglaterra & Tasas de reporto & 2 semanas (nromedio) \\
\hline Suecia & Tasa de reporto & 7 días \\
\hline Japón & Tasa de descuento oficial & 1 día \\
\hline Corea & Tasa de fondeo diario & 1 día \\
\hline Israel & Tasa de interés nominalefectiva & 1'́á \\
\hline Polonia & Tasa de descuento & 1 día \\
\hline Brasil & Tasabase & 1día \\
\hline Colombia & $\begin{array}{l}\text { Tasa de intervención y franja de } \\
\text { intervención }\end{array}$ & 7 días \\
\hline Chile & Tasa de instancia monetaria & 1 día \\
\hline Unión Monetaria Europea & Tasa de refinanciamiento & 2 semanas \\
\hline
\end{tabular}

Bajo el sistema de objetivos sobre "non-Borrowed Reserves" el Fed subastaba diariamente un monto objetivo de "non-Borrowed Reserves", mientras que el resto de los recursos que requería el sistema en el corto plazo los proveía a una tasa de castigo a través de la ventanilla de descuento. De este modo, cada vez que el Banco Central reducía el monto de "non-Borrowed Reserves", una mayor cantidad de recursos se proporcionaba a la tasa de descuento, presionando así al alza de la tasa de interés de corto plazo. Después de 1982 el Fed volvió a instrumentar la política monetaria con base en la fijación la tasa de fondos federales ${ }^{5}$.

5 Para una descripción detallada de los instrumentos utilizados por la autoridad monetaria en los Estados Unidos, véase Walsh (1998). 
Bajo el sistema de "Settlement Balances" en Nueva Zelanda los bancos comerciales podían tener saldos acreedores en su cuenta única en el Banco Central, la cual pagaba un rendimiento menor que el de mercado (300 puntos base en 1998) y de cero a todo saldo superior a un límite, sin permitirse los sobregiros. La única fuente adicional de liquidez inmediata eran los Bonos de la Reserva, ya que el Banco Central estaba dispuesto a tomar a descuento todos los bonos con madurez efectiva menor que 28 días. Al aceptar estos bonos a descuento, el Banco Central cobraba un castigo (igual a 90 puntos base en 1998) que se aplicaba al vencimiento del papel descontado ${ }^{6}$. Esto último hacía que resultara más barato para los bancos financiar operaciones imprevistas a través de sus saldos en la cuenta única en el Banco Central. Este saldo constituía la demanda por "Settlement Balances". El Banco Central determinaba sus operaciones de mercado abierto de tal forma que el sistema financiero cerrara con un saldo acreedor igual a un objetivo preestablecido, lo que constituía el objetivo de "Settlement Balances". Al disminuir este objetivo el Banco Central generaba mayor competencia por los recursos, presionando a la tasa de interés de corto plazo al alza. En marzo de 1999, la instrumentación de la política monetaria en Nueva Zelanda pasó de este sistema, en el cual el Banco Central manipulaba indirectamente las condiciones del mercado a través del mecanismo descrito, a otro en donde el Banco Central establece un objetivo para la tasa de interés.

Bajo los regímenes descritos de "Non-Borrowed Reserves" y de "Settlement Balances", al igual que bajo el régimen de saldos acumulados vigente en México, el Banco Central fija un objetivo no sobre la tasa de interés de corto plazo sino sobre la cantidad de recursos que proporcionan a tasa de mercado y/o a tasa de castigo, afectando a la tasa de interés sólo de manera indirecta. En México, bajo el régimen de saldos acumulados, explicado en la Sección II, el Banco Central modifica la cantidad de recursos que provee al mercado para que una cantidad fija ("el corto") se otorgue a tasa de castigo, en tanto que el resto de los recursos los que se asignan a tasa de mercado. La situación resultaba similar en el caso del sistema de "Settlement Balances", en donde al reducir el objetivo el Banco Central propiciaba que los bancos comerciales tuvieran que satisfacer sus necesidades de liquidez adicional a través de redescuentos. Finalmente, bajo el régimen de “non-Borrowed Reserves" el Fed establecía un objetivo sobre los fondos que otorgaba a tasa de mercado, y el monto restante era proporcionado a una tasa de castigo.

6 De modo que descontar un bono con madurez efectiva de tres días se castigaba con 270 puntos base en 1998. Dada la necesidad de los bancos comerciales de financiar operaciones a un día, este recurso podía resultar muy costoso. 


\section{III.1. Ventajas y Desventajas de un Instrumento Cuantitativo y de una Tasa de Objetivo.}

En la selección del instrumento de política monetaria el Banco Central considera factores tanto internos como externos. Por un lado, el instrumento determina la claridad de la señal de política monetaria así como la efectividad con que ésta afecta a la tasa de interés de corto plazo, al resto de la curva de rendimientos, a los precios de otros activos, al tipo de cambio y a las expectativas de inflación. Esto determina su impacto sobre los componentes de la demanda agregada y sobre el proceso de formación de precios en la economía. Además, el instrumento de política monetaria propiciará que la volatilidad proveniente del exterior se refleje en mayor medida en movimientos de las tasas de interés o alternativamente en el tipo de cambio.

Entre las ventajas que tiene un instrumento que afecta las condiciones del mercado de dinero a través de una restricción cuantitativa, está la de incorporar a la determinación de la tasa de interés toda la información de los participantes del mercado, así como la del Banco Central. Esto ocurre ya que aquel instrumento funciona únicamente como una señal que interactúa con los ajustes realizados por los agentes en el mercado. Ante condiciones de alta volatilidad, lo anterior implica que la tasa de interés de corto plazo se modifica de manera automática, permitiendo a ésta una gran flexibilidad y propiciando que las perturbaciones externas se distribuyan entre cambios en la tasa de interés y en el tipo de cambio.

Por otro lado, es indudable que el instrumento cuantitativo es compatible con distintos niveles de la tasa de interés, ya que simplemente determina el monto de los recursos que el Banco Central ofrece a los bancos comerciales a una tasa de castigo, y esta última se define en función de la tasa de interés de mercado. Es por esto que, como instrumento de política monetaria, al ser compatible con distintos niveles de tasas de interés su efecto sobre éstas es más incierto, ya que depende de las condiciones que prevalezcan en los mercados financieros.

La instrumentación de la política monetaria con base en un objetivo para la tasa de interés de corto plazo constituye una señal más directa. El uso de este instrumento se ha caracterizado en la práctica por la gradualidad de las acciones del Banco Central. Esto se puede deber a que, en situaciones de incertidumbre, errores en el cálculo de la tasa objetivo pueden repercutir sobre la capacidad del Banco Central para controlar la inflación. Además, variaciones frecuentes en la tasa 
de interés objetivo, implican necesariamente cambios constantes de sentido en la postura de política monetaria del Banco Central, lo cual podría generar confusión en el mercado ${ }^{7}$.

A continuación se analiza el comportamiento de la tasa de interés objetivo en los países cuyos bancos centrales la utilizan como instrumento de política. Además, aunque en México la instrumentación de la política monetaria no se ha basado en la fijación de una tasa objetivo, se presenta asimismo una estimación de la que hubiera sido la tasa “objetivo". Ello con la intención de hacer una comparación con la conducción de la política monetaria en otros países.

Para estimar la tasa "objetivo" en México, ésta se supone inicialmente igual al promedio semanal de la tasa de "fondeo". A continuación, se considera que la tasa "objetivo" permanece constante siempre que la variación semanal, en valor absoluto, en la tasa de "fondeo" sea menor que 150 puntos base. Finalmente, cuando dicha variación resulta mayor que 150 puntos base, la nueva tasa "objetivo" se iguala a la última tasa de "fondeo" promedio. En la Gráfica 9 se muestra el comportamiento de la tasa de "fondeo" observada y de la tasa "objetivo" estimada con base en esta metodología. Como puede observarse el comportamiento de la tasa "objetivo" estimada para México se hubiera caracterizado no sólo por modificaciones frecuentes, sino por cambios frecuentes en la dirección de la postura de política monetaria.

7 Algunos autores han analizado el gradualismo de la política monetaria en los Estados Unidos. Entre estos Cukierman (1991) sostiene que una de las razones por las que el Fed tiene un elemento de "suavización" de los movimientos de la tasa de interés en su función de reacción es el deseo de proteger al sector privado de crisis financieras. Por otro lado, Sack (1998), encuentra que éste elemento de gradualismo en la función de reacción del Fed se puede explicar al introducir incertidumbre en los parámetros de un modelo estructural de la economía. 


\section{Gráfica 9 \\ Tasa de Interés de "Fondeo" y “Objetivo Hipotético"}

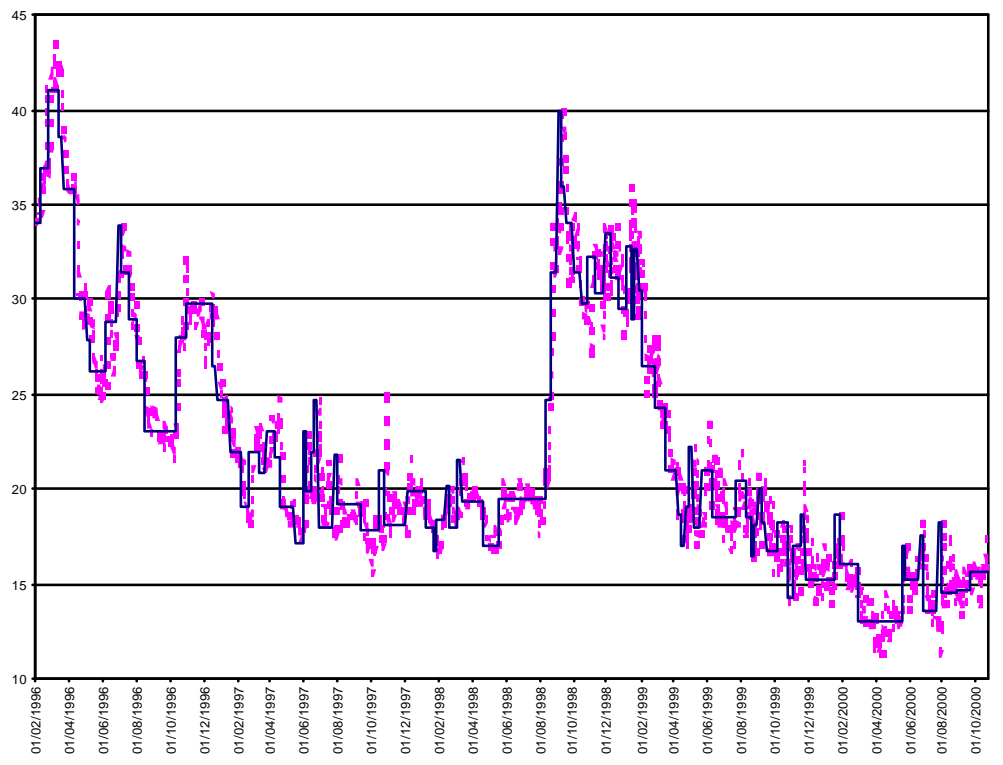

En el Cuadro 3 se presentan los cambios observados en la tasa objetivo de un conjunto de países, así como los estimados para México con base en la metodología descrita. A partir de estos resultados es posible constatar que la política monetaria de los bancos centrales que utilizan una tasa objetivo como instrumento se caracteriza no sólo por movimientos graduales en las tasas, sino también por escasos cambios de dirección. Cuando se compara éste comportamiento con el de la tasa "objetivo" estimada para México, resulta que para aproximar las fluctuaciones observadas en la tasa de "fondeo" el Banco de México hubiera tenido que realizar un número relativamente elevado de modificaciones en la tasa "objetivo".

En el último renglón del Cuadro 3 se incluye la frecuencia de los cambios de dirección en la tasa objetivo. Como se puede apreciar, en la mayoría de los países la dirección de la política monetaria ha cambiado con una probabilidad que oscila 9 y 30 por ciento. En contraste, con la estimación para México, la probabilidad correspondiente es de 57 por ciento. Esto decir, más de la mitad de las variaciones en la tasa "objetivo" estimada han implicado un cambio de dirección de la política monetaria ${ }^{8}$.

8 Cuando se lleva a cabo el ejercicio con base en el comportamiento de la tasa de Cetes de 28 días, el número de cambios durante el año en la tasa "objetivo" se asemeja más al promedio observado en otros países. Sin embargo, la probabilidad de cambio de dirección resulta de 52 por ciento, aún muy superior a la registrada en otros países. 
Cuadro 3

Cambios en la Tasa Objetivo

\begin{tabular}{|c|c|c|c|c|c|c|c|c|c|c|c|c|c|c|}
\hline & \multicolumn{2}{|c|}{ Australia } & \multicolumn{2}{|c|}{ Alemania ${ }^{*}$} & \multicolumn{2}{|c|}{ Israel } & \multicolumn{2}{|c|}{ Canadá } & \multicolumn{2}{|c|}{ Inglaterra } & \multicolumn{2}{|c|}{ EU } & \multicolumn{2}{|c|}{ México } \\
\hline & Cambio & & Cambio & & Cambio & & Cambio & & Cambio & & & ambio & & ambio \\
\hline & Total & Dirección & Total & Dirección & Total & Dirección & Total & Dirección & Total & Dirección & Total & Dirección & Total & Dirección \\
\hline 1996 & 3 & $\begin{array}{l}(+) 0 \\
(-) 3\end{array}$ & 1 & $\begin{array}{l}(+) 0 \\
(-) 1\end{array}$ & 9 & $\begin{array}{l}(+) 4 \\
(-) 5\end{array}$ & 16 & $\begin{array}{l}(+) 4 \\
(-) 12\end{array}$ & 4 & $\begin{array}{l}(+) 1 \\
(-) 3\end{array}$ & 1 & $\begin{array}{l}\text { (+) } 0 \\
(-) 1\end{array}$ & 17 & $\begin{array}{l}(+) 6 \\
(-) 11\end{array}$ \\
\hline 1997 & 2 & $\begin{array}{l}(+) 0 \\
(-) 2\end{array}$ & 0 & $\begin{array}{l}(+) 0 \\
(-) 0\end{array}$ & 4 & $\begin{array}{l}(+) 1 \\
(-) 3\end{array}$ & 4 & $\begin{array}{l}(+) 4 \\
(-) 0\end{array}$ & 5 & $\begin{array}{l}(+) 5 \\
(-) 0\end{array}$ & 1 & $\begin{array}{l}+(+) 1 \\
(-) 0\end{array}$ & 19 & $\begin{array}{l}(+) 8 \\
(-) 11\end{array}$ \\
\hline 1998 & 1 & $\begin{array}{l}(+) 0 \\
(-) 1\end{array}$ & 0 & $\begin{array}{l}(+) 0 \\
(-) 0\end{array}$ & 10 & $\begin{array}{l}(+) 2 \\
(-) 8\end{array}$ & 5 & $\begin{array}{l}(+) 2 \\
(-) 3\end{array}$ & 4 & $\begin{array}{l}(+) 1 \\
(-) 3\end{array}$ & 3 & $\begin{array}{l}(+) 0 \\
(-) 3\end{array}$ & 21 & $\begin{array}{l}(+) 9 \\
(-) 12\end{array}$ \\
\hline 1999 & 1 & $\begin{array}{l}(+) 1 \\
(-) 0 \\
\end{array}$ & 2 & $\begin{array}{l}(+) 1 \\
(-) 1\end{array}$ & 6 & $\begin{array}{l}(+) 0 \\
(-) 6\end{array}$ & 3 & $\begin{array}{l}(+) 1 \\
(-) 2\end{array}$ & 6 & $\begin{array}{l}(+) 2 \\
(-) 4\end{array}$ & 3 & $\begin{array}{l}(+) 3 \\
(-) 0\end{array}$ & 26 & $\begin{array}{l}(+) 11 \\
(-) 15\end{array}$ \\
\hline 2000 & 4 & $\begin{array}{l}\text { (+) } 4 \\
(-) 0\end{array}$ & 6 & $\begin{array}{l}\text { (+) } 6 \\
(-) 0\end{array}$ & 8 & $\begin{array}{l}(+) 0 \\
(-) 8\end{array}$ & 3 & $\begin{array}{l}(+) 3 \\
(-) 0\end{array}$ & 2 & $\begin{array}{l}(+) 2 \\
(-) 0\end{array}$ & 3 & $\begin{array}{l}(+) 3 \\
(-) 0\end{array}$ & 11 & $\begin{array}{l}(+) 6 \\
(-) 5\end{array}$ \\
\hline $\begin{array}{c}\text { Probabilidad de } \\
\text { cambio en la tasa } \\
\text { objetivo (Por ciento) }\end{array}$ & & 9 & & 11 & & 14 & & 26 & & 14 & & 27 & & 57 \\
\hline
\end{tabular}

Es importante notar, sin embargo, que de no haber ocurrido las modificaciones observadas en la tasa de "fondeo", ello probablemente se habría reflejado en movimientos más abruptos del tipo de cambio. Lo anterior, aunado al alto pass-through del tipo de cambio a los precios en México, hubiera afectado desfavorablemente la trayectoria de la inflación.

Por tanto, los cambios tan frecuentes observados en las condiciones del mercado de dinero en México han sido necesarios para mantener la tasa de inflación en una trayectoria congruente con la meta del Banco Central. Lo anterior, debido fundamentalmente a dos factores:

a) la volatilidad del rendimiento de los bonos que el gobierno coloca en los mercados internacionales de capital, y

b) el efecto de las variaciones del tipo de cambio sobre el comportamiento de los precios.

El instrumento de la política monetaria propicia que el ajuste ante las perturbaciones tanto internas como externas se distribuyan ya sea entre fluctuaciones de la tasa de interés o del tipo de cambio. A la luz del alto pass-through, un factor coadyuvante para mantener una tasa de inflación que converge hacia la meta del Banco Central, ha sido la distribución de la reacción a las perturbaciones entre la tasa de interés y el tipo de cambio. En las siguientes dos secciones se analiza como la instrumentación de la política monetaria en México ha estado condicionada por la alta volatilidad del rendimiento de los bonos gubernamentales emitidos en el exterior y por el alto passthrough.

\section{III.2. La Volatilidad de la Tasa Externa}

Para examinar el efecto que la volatilidad del rendimiento de los bonos del gobierno denominados en moneda extranjera tiene sobre las condiciones del mercado de dinero interno, hay 
que considerar que la volatilidad se traduce ya sea en movimientos del tipo de cambio o de la tasa de interés, dependiendo del instrumento de política monetaria. Esto se puede ver de manera sencilla a partir de la ecuación de la paridad de tasas de interés. Bajo el supuesto de movilidad de capitales se tiene que:

$$
i_{t}=i_{t}^{*}+\left(s_{t+1}-s_{t}\right)
$$

donde $i$ es la tasa de interés nacional, $i^{*}$ es el rendimiento de un bono del gobierno mexicano denominado en dólares y $\left(\mathrm{s}_{\mathrm{t}+1}-\mathrm{s}\right)$ es la depreciación (o apreciación) cambiaria esperada. Despejando y calculando las varianzas de ambos lados de la ecuación, se obtiene que la suma de la varianza de la tasa de interés y la de la depreciación cambiaria es igual a la varianza en el rendimiento del bono en dólares ${ }^{9}$.

$$
\operatorname{var}(i)+\operatorname{var}(\Delta s) \pm \operatorname{cov}(i, \Delta s)=\operatorname{var}\left(i^{*}\right)
$$

Lo anterior implica que en el caso en el que el Banco Central fijara un objetivo para la tasa de interés de corto plazo, la volatilidad externa se transmitiría principalmente al mercado cambiario. Por otra parte, cuando el Banco Central permite fluctuaciones en las tasas de corto plazo las perturbaciones externas se distribuyen entre ajustes en la tasa de interés y en el tipo de cambio. En el Cuadro 4 se presenta la desviación estándar del rendimiento de los bonos denominados en moneda extranjera que el gobierno coloca en los mercados de capital. Como es posible apreciar, esta medida de la volatilidad de dicho rendimiento ha sido mucho mayor para los bonos mexicanos que para los títulos de otros países con régimen de libre flotación cambiaria.

\section{Cuadro 4}

\section{Desviación Estándar del Rendimiento de los Bonos del Gobierno en Moneda Extranjera} (Puntos Base)

\begin{tabular}{ccccc}
\hline & MÉXICO & CANADÁ & AUSTRALIA & NUEVAZELANDA \\
\hline $\mathbf{9 7 - I}$ & 20 & 9 & 10 & N.D. \\
$\mathbf{9 7 - I I}$ & 15 & 7 & 8 & 7 \\
$\mathbf{9 7 - I I I}$ & 11 & 8 & 8 & 8 \\
$\mathbf{9 7 - I V}$ & 28 & 7 & 7 & 7 \\
\hline $\mathbf{9 8 - I}$ & 10 & 8 & 10 & 8 \\
$\mathbf{9 8 - I I}$ & 11 & 5 & 5 & 7 \\
$\mathbf{9 8 - I I I}$ & 54 & 7 & 7 & 6 \\
$\mathbf{9 8 - I V}$ & 30 & 13 & 15 & 11 \\
\hline $\mathbf{9 9 - I}$ & 31 & 10 & 11 & 10 \\
$\mathbf{9 9 - I I}$ & 21 & 11 & 10 & 9 \\
$\mathbf{9 9 - I I I}$ & 14 & 11 & 9 & 9 \\
$\mathbf{9 9 - I V}$ & 13 & 9 & 10 & 9 \\
\hline $\mathbf{0 0 - I}$ & 21 & 8 & 8 & 8 \\
$\mathbf{0 0 - I I}$ & 23 & 14 & 14 & 13 \\
$\mathbf{0 0 - I I I}$ & 12 & 6 & 9 & 6 \\
\hline
\end{tabular}

9 El rendimiento de los bonos que coloca el gobierno en el exterior incluye tanto la tasa de interés externa como la prima por el riesgo país. 
Para analizar el efecto que esta elevada variabilidad de la tasa externa ha tenido sobre el comportamiento del tipo de cambio y de la tasa de interés interna, en los Cuadros 5 y 6 se compara la volatilidad de estas variables en México con la observada en otros países. Si bien la volatilidad cambiaria en México no ha diferido significativamente de la de otros países (Cuadro 5), la volatilidad de la tasa de interés de "fondeo" sí ha sido considerablemente mayor (Cuadro 6).

\section{Cuadro 5}

Volatilidad del Tipo de Cambio

(Por ciento)*

\begin{tabular}{rcccccc}
\hline & Alemania** $^{*}$ Inglaterra & Canadá & Australia & Nueva Zelanda & México \\
\cline { 2 - 7 } $96-I$ & 6.4 & 5.8 & 3.7 & 6.2 & 5.4 & 6.4 \\
$96-I I$ & 6.6 & 5.4 & 3.1 & 6.3 & 5.8 & 5.1 \\
\hline $97-I$ & 9.8 & 8.5 & 4.8 & 7.4 & 6.0 & 4.7 \\
$97-I I$ & 9.8 & 8.0 & 4.2 & 10.3 & 8.6 & 10.7 \\
$98-I$ & 8.1 & 7.1 & 4.3 & 11.9 & 12.5 & 6.7 \\
$98-I I$ & 9.2 & 7.3 & 7.0 & 15.0 & 15.1 & 11.1 \\
\hline $99-I$ & 8.9 & 6.9 & 5.7 & 9.9 & 9.5 & 9.9 \\
$99-I I$ & 10.0 & 7.3 & 5.2 & 8.6 & 10.1 & 7.1 \\
$2000-Q 1$ & 12.2 & 7.3 & 5.0 & 10.7 & 11.2 & 5.9 \\
$2000-Q 2$ & 12.5 & 8.1 & 5.1 & 11.4 & 13.5 & 7.2 \\
$2000-Q 3$ & 11.0 & 8.1 & 4.5 & 10.7 & 11.4 & 9.1 \\
\hline ** Para el período 99-00 se utilizaron datos del Banco Central Europeo. & & & \\
* Coeficiente de variación del tipo de cambio de cada país con respecto al dólar de los Estados Unidos. &
\end{tabular}

Si el Banco de México hubiera adoptado un objetivo para la tasa de interés, dada la experiencia internacional y suponiendo que el Banco Central no hubiese enviado señales ambiguas a los mercados, la variabilidad de la tasa de "fondeo" probablemente hubiera resultado menor. Sin embargo, a la luz de las consideraciones anteriores, ello hubiera causado un aumento en la volatilidad cambiaria, lo cual debido al elevado pass-through hubiera derivado en una mayor inflación.

El punto anterior se puede ilustrar con referencia a la experiencia de Nueva Zelanda. En este país, como se vio en la primera sección del documento, la instrumentación de la política monetaria hasta febrero de 1999 fue similar a la de México. A partir de entonces empezó a fijar un objetivo para la tasa de interés de corto plazo. Como se observa en el Cuadro 6, la adopción de un instrumento de tasas de interés en marzo de 1999 propició una menor variabilidad de las tasas de interés. En contraste, la volatilidad cambiaria durante 1999 y 2000 resultó considerablemente mayor que la observada en 1996 y 1997 (Cuadro 5). En esta comparación se excluye el período que va del segundo semestre de 1997 a finales de 1998, por estar contaminado por la volatilidad generada por las crisis de Asia y Rusia.

La disminución en la variabilidad de la tasa de interés en Nueva Zelanda también pudo haberse debido a una menor volatilidad de la tasa externa, del riesgo país o de los términos de intercambio. Para controlar por estos efectos del entorno externo, se tomó la variabilidad observada 
en la tasa de interés y en el tipo de cambio de Australia, una economía con características muy similares. A partir de la adopción del instrumento de tasa de interés en Nueva Zelanda en marzo de 1999, la diferencia entre la volatilidad de la tasa de interés en ambos países disminuyó significativamente (Cuadro 6). Por otro lado, en el Cuadro 5, se observa que la volatilidad del tipo de cambio en Nueva Zelanda ha sido mayor que en Australia durante la segunda mitad del 1999 y lo que va de 2000. En contraste, durante la mayor parte de 1996 y 1997 la de Australia había sido superior.

\section{Cuadro 6}

Volatilidad de la Tasa de Interés de Corto Plazo

(Por ciento)*

\begin{tabular}{|c|c|c|c|c|c|c|}
\hline & Alemania** & Inglaterra & Canadá & Australia & Nueva Zelanda & México \\
\hline I-97 & 4.2 & 0.7 & 0.2 & 0.6 & 3.5 & 20.6 \\
\hline 97-II & 5.0 & 1.0 & 0.6 & 0.7 & 5.0 & 7.1 \\
\hline $\begin{array}{c}\text { I-98 } \\
98-I\end{array}$ & $\begin{array}{l}3.1 \\
2.0 \\
\end{array}$ & $\begin{array}{l}0.5 \\
2.2 \\
\end{array}$ & $\begin{array}{l}0.7 \\
1.3 \\
\end{array}$ & $\begin{array}{l}0.1 \\
0.2\end{array}$ & $\begin{array}{c}3.2 \\
14.4 \\
\end{array}$ & $\begin{array}{c}5.1 \\
57.9 \\
\end{array}$ \\
\hline וI-99 & $\begin{array}{r}5.8 \\
0.5 \\
\end{array}$ & $\begin{array}{l}3.7 \\
1.9 \\
\end{array}$ & $\begin{array}{l}0.2 \\
0.2\end{array}$ & $\begin{array}{l}0.1 \\
0.1 \\
\end{array}$ & $\begin{array}{l}5.7 \\
0.3 \\
\end{array}$ & $\begin{array}{l}20.6 \\
5.3 \\
\end{array}$ \\
\hline 2000-Q1 & 0.2 & 5.7 & 0.4 & 0.7 & 1.0 & 6.2 \\
\hline 2000-Q2 & 0.9 & 3.0 & 0.6 & 0.4 & 0.9 & 9.1 \\
\hline $2000-Q 3$ & 0.5 & 3.5 & 0.0 & 0.1 & 0.1 & 11.5 \\
\hline
\end{tabular}

Con el objeto de estudiar la distribución del efecto de las fluctuaciones en el rendimiento de los bonos colocados en el exterior sobre la tasa de interés interna y sobre el tipo de cambio, a continuación se analiza el comportamiento conjunto de estas tres variables para el caso de México, en el contexto de libre flotación del tipo de cambio y el régimen de saldos acumulados. En este ejercicio se estima un vector autorregresivo que incluye el rendimiento de los bonos colocados en el exterior, la variación logarítmica en el nivel del tipo de cambio y la tasa de interés de "fondeo" durante el período que se extiende del 5 de marzo de 1996 a la fecha ${ }^{10}$. En la parte superior de la Gráfica 10 es posible observar como en México un impulso de una desviación estándar en el rendimiento del bono externo provoca aumentos estadísticamente significativos tanto en la tasa de interés como en el tipo de cambio. Además, se obtiene evidencia de un efecto positivo y significativo de la depreciación cambiaria sobre la tasa de interés.

10 Las observaciones son diarias, el orden de exogeneidad de las variables adoptado va del rendimiento externo a la depreciación cambiaria a la tasa de interés. El número de rezagos no altera el resultado. 


\section{Gráfica 10 \\ Funciones Impulso Respuesta}

Respuesta del Tipo de Cambio a una Perturbación en el Rend. Bono Externo
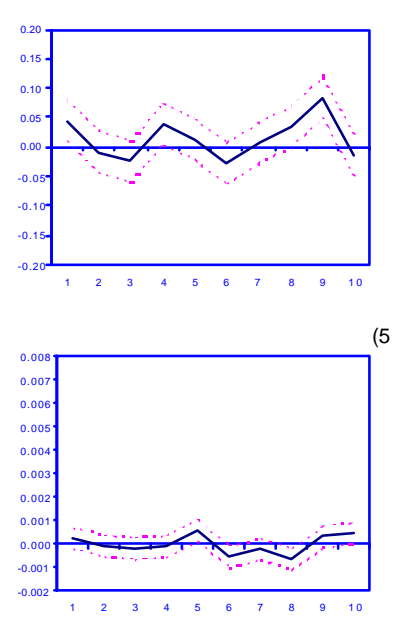

Respuesta de la Tasa de Interés a una Perturbación en el Rend. Bono Externo

( 5 de Marzo de 1996 a la fecha)

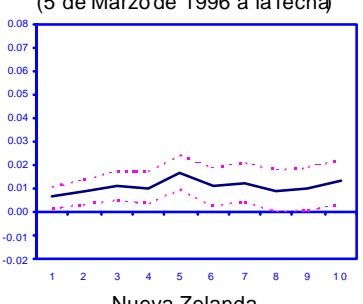

Nueva Zelanda

Marzo de 1996 al 26 de Febrero de 1999

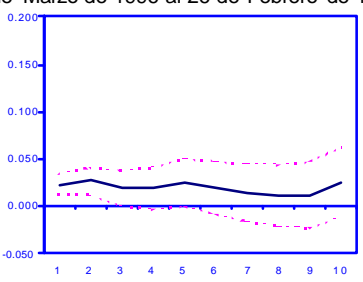

Australia

(5 de Marzo de 1996 al 26 de Febrero de 1999
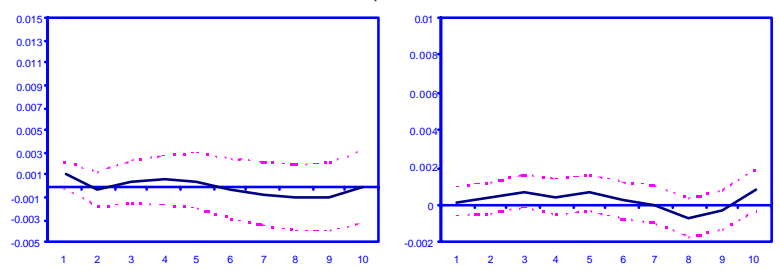

Nueva Zelanda

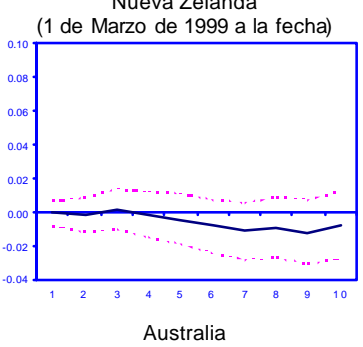

Australia
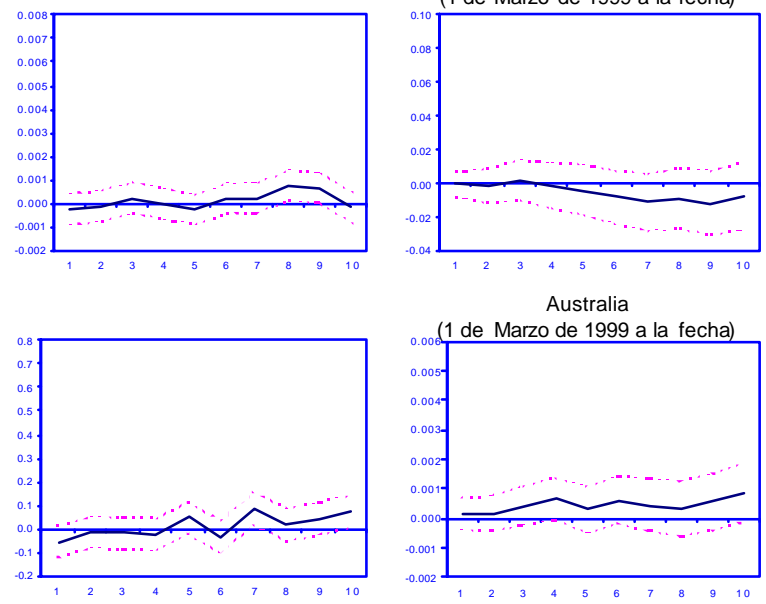

Respuesta de la Tasa de Interés a una Perturbación en el Tipo de Cambio
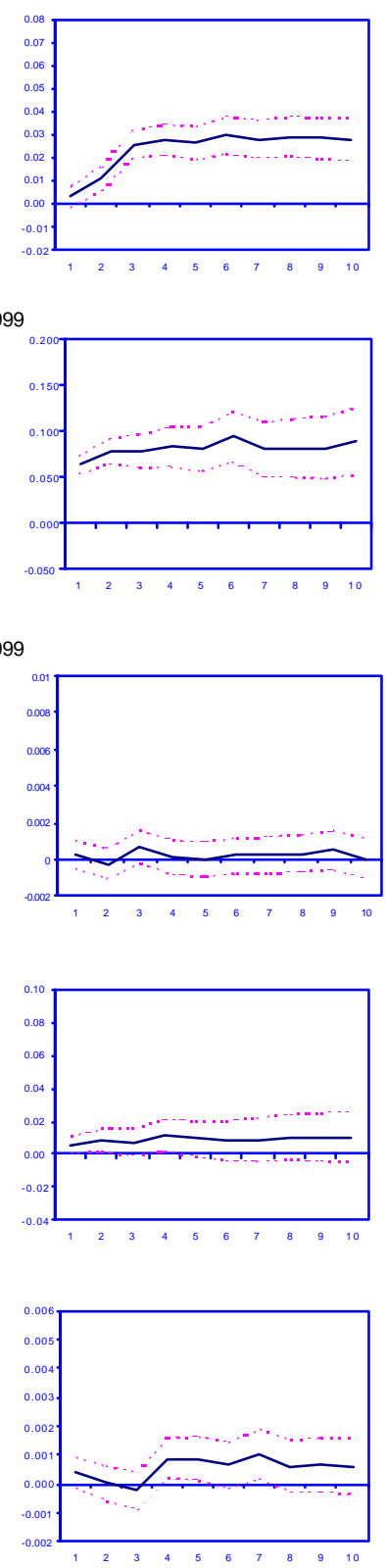

Este último efecto puede deberse a dos factores. En primera instancia, a que al depreciarse el tipo de cambio, debido al aumento en la tasa de interés externa o en el riesgo país, ocurre un deterioro de las expectativas de inflación, el cual induce un incremento en la tasa de interés. Por otro lado, en el contexto de un instrumento de política monetaria que afecta las condiciones de mercado a través de una restricción cuantitativa, éste efecto se puede interpretar como producto de 
la reacción restrictiva del Banco Central. Al observar el efecto de la perturbación externa sobre el tipo de cambio éste intensifica la restricción monetaria, dado que la depreciación del tipo de cambio es capaz de contaminar la expectativas de inflación y la inflación misma.

Para analizar si este efecto estuvo presente en el caso de Nueva Zelanda durante el período en el cual el Banco Central instrumentó la política monetaria con base en el régimen de "Settlement Balances", a continuación se lleva a cabo el mismo ejercicio para ese país durante el período que se extiende del 5 de marzo de 1996 al 26 de febrero de 1999.

En el segundo renglón de la Gráfica 10 es posible observar que la perturbación, de una desviación estándar, en el rendimiento externo del bono neozelandés provoca un aumento marginalmente significativo y rezagado en la depreciación cambiaria y un efecto transitorio positivo y significativo sobre la tasa de interés de corto plazo. Además, la mayor depreciación cambiaria parece generar incrementos significativos en la tasa de interés. Al igual que en el caso de México, esto último puede indicar que el Banco Central reacciona intensificando la restricción monetaria al ver los efectos de laperturbación externa sobre la depreciación cambiaria, y la posible transmisión de éstos a la trayectoria de la inflación. Cuando se realiza a cabo el ejercicio para el caso de Australia durante el mismo período, en el renglón tres de la Gráfica 10 se observa que ninguno de estos efectos resulta significativo.

A continuación se analiza el comportamiento de las mismas variables para el período que comprende del 1o. de marzo de 1999 al 26 de julio de 2000 (posterior a la adopción del instrumento de tasa de interés en Nueva Zelanda). En el renglón cuatro de la Gráfica 10 se observa como el cambio de régimen en Nueva Zelanda ha causado que la tasa de interés ya no responda a las perturbaciones externas, y que ésta apenas responda transitoriamente a los cambios en la depreciación cambiaria. En el siguiente renglón de la misma gráfica se observa que durante este período en Australia solamente la respuesta de la tasa de interés a la depreciación cambiaria resulta marginalmente significativa y ello con cierto rezago.

En esta sección se ha mostrado que la instrumentación de la política monetaria condiciona el efecto que las fluctuaciones en la tasa externa tienen sobre la tasa de interés y sobre el tipo de cambio. A continuación se discute cómo el resultado anterior cobra relevancia siempre que las fluctuaciones cambiarias tienen efectos duraderos sobre el crecimiento de los precios, ya sea directamente o a través de alteraciones en las expectativas de inflación. 


\section{III.3 El Efecto del Tipo de Cambio sobre los Precios}

El elevado pass-through que existe en México se puede ilustrar de manera sencilla mediante la comparación de la velocidad de respuesta de los precios a variaciones en el tipo de cambio, estimada a partir de modelos econométricos para México y otros países. En la Gráfica 11 es posible apreciar que el impacto de largo plazo de una depreciación cambiaria de 10 por ciento sobre los precios es mayor en México que en Australia ${ }^{11}$. Se observa, además, que en México el 50 por ciento ocurre en dos trimestres, y el 82 por ciento durante el primer año. Esto contrasta con lo observado en Australia, en donde en dos trimestres se observa tan solo el 7 por ciento del efecto, y durante el primer año apenas el 14 por ciento del efecto total.

\section{Gráfica 11}

\section{Velocidad de Respuesta de los Precios a una Depreciación de $10 \%$ en el Tipo de Cambio}

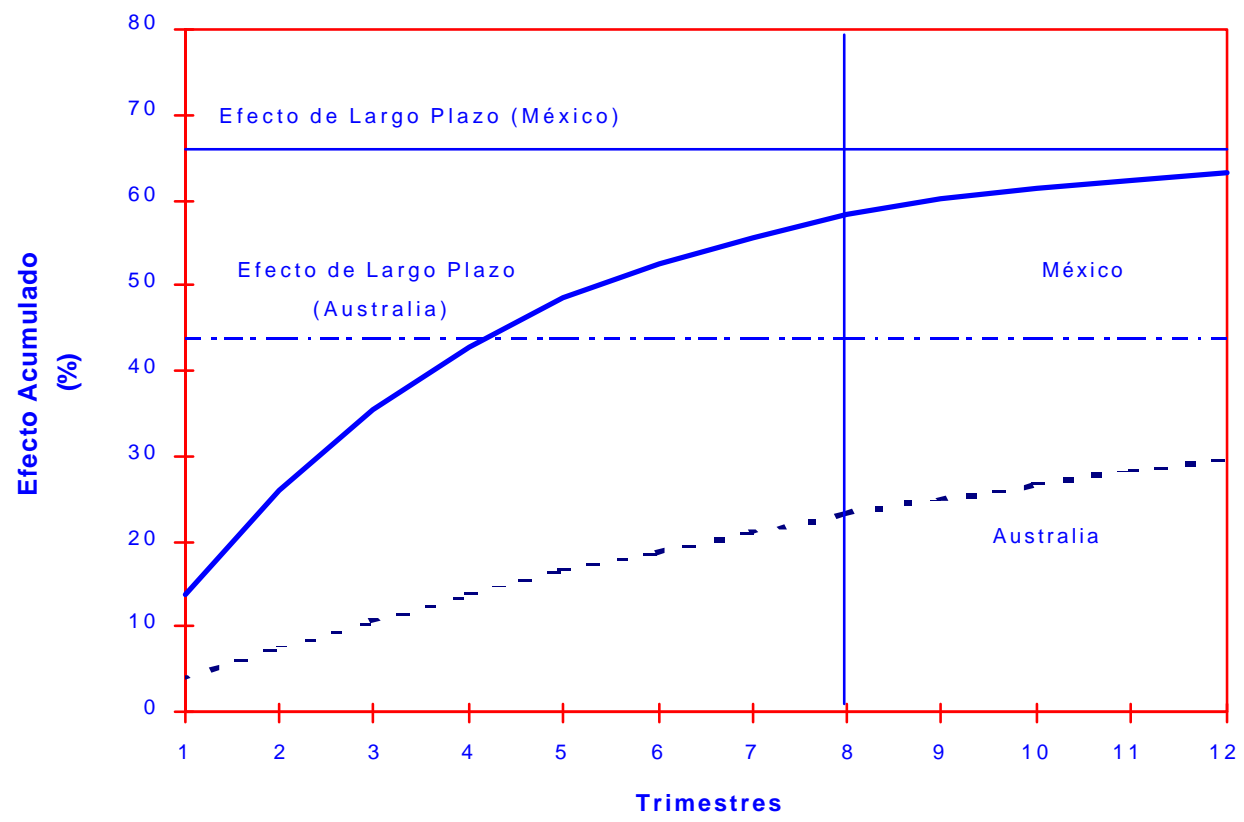

Las fluctuaciones del tipo de cambio afectan al índice de precios ya sea directamente a través de su efecto sobre los precios de los bienes comerciables, o indirectamente a través del cambio en la expectativa de inflación, la cual determina tanto los ajustes salariales como las modificaciones de otros precios en la economía. La importancia del primer canal está determinada

11 De Brower y Ericsson (1998) llevan a cabo una estimación del pass-through para la economía australiana. Garcés (1999) realiza este mismo análisis para el caso de México. Asimismo, encuentra que en el caso de México la respuesta del índice de precios depende de la magnitud de la depreciación. Esto es, cuando la depreciación es mayor que un determinado límite, la respuesta de los precios resulta 1 a 1 en el largo plazo. Es decir, el pass-through es completo. En el caso de depreciaciones menos pronunciadas, el coeficiente estimado resulta menor que uno. 
por el grado de apertura de la economía, así como por la estructura de mercado en el sector de los bienes comerciables ${ }^{12}$. El segundo canal se refiere a la respuesta de las expectativas de inflación de los agentes ante variaciones en el tipo de cambio.

Existen varias razones por las que en México el efecto del tipo de cambio sobre los precios ha sido mayor que el observado en otras economías. La primera es la integración de la economía a través de la apertura comercial. Lo anterior aumenta la sensibilidad de los procesos productivos y de la demanda agregada a las fluctuaciones en el tipo de cambio. En México la proporción del comercio total al PIB pasó de 15 por ciento en 1990 a 58 por ciento en 1999, mientras que para Australia esta cifra creció del 26 por ciento al 31 por ciento durante el mismo período. Por otro lado, el historial de alta inflación y crisis de balanza de pagos seguidas de sorpresas devaluatorias, ha contribuido a exacerbar en México la asociación de las expectativas de inflación con los movimientos del tipo de cambio. En la Gráfica 12 se puede apreciar que la depreciación cambiaria, además de preceder a la inflación, tiene una alta correlación con ésta.

\section{Gráfica 12}

\section{Depreciación Cambiaria y Tasa de Inflación en México}

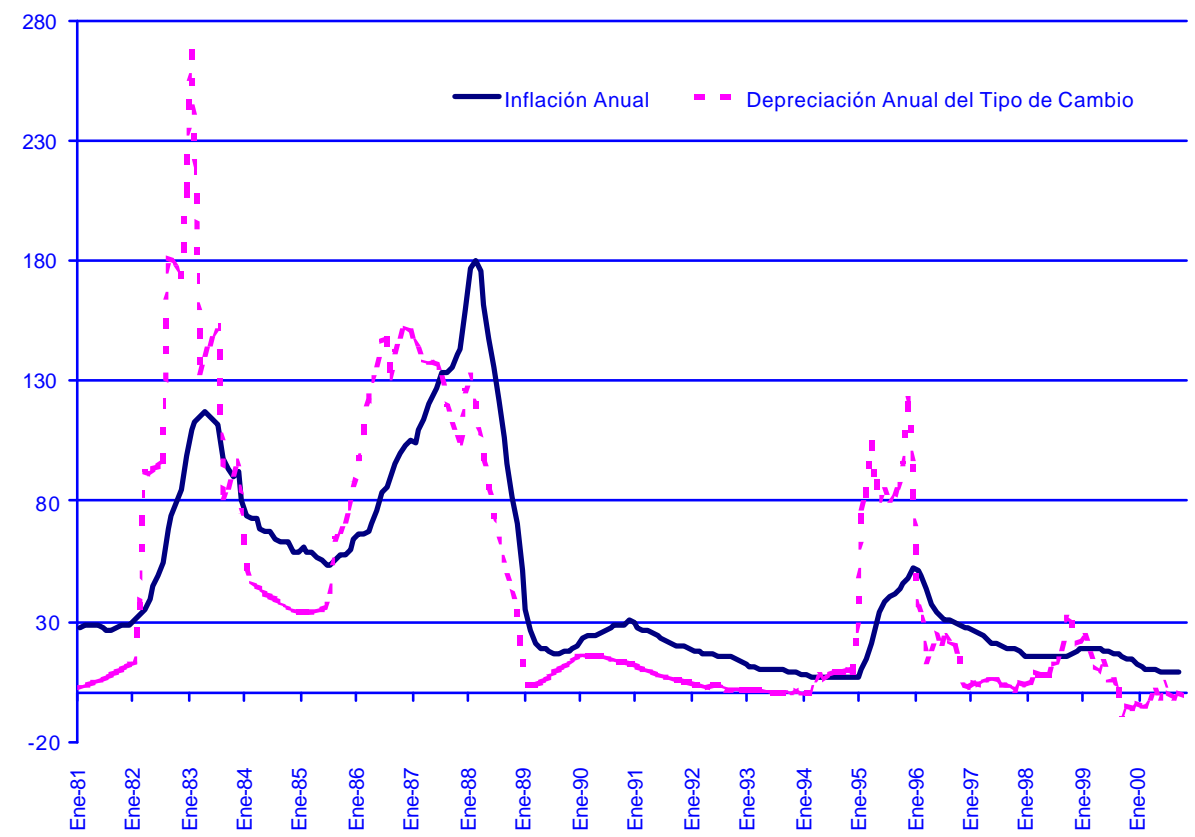

12 La respuesta de los precios de los bienes comerciables a las variaciones en el tipo de cambio está condicionada a su vez por la estructura de mercado de estos bienes. De ésta dependerá la disposición de los participantes para hacer uso del cambio en precios relativos provocado por la depreciación cambiaria para mantener o lograr una mayor penetración de mercado, disminuyendo sus márgenes de ganancia. La importancia de estos factores en la economía mexicana fue estudiada por Conesa (1998). 
Para evaluar el efecto que tienen las fluctuaciones cambiarias sobre las expectativas de inflación, y establecer si éste ha disminuido recientemente, se estimó una regresión lineal que busca explicar la variación semanal en la expectativa de inflación para los siguientes doce meses en función de la depreciación semanal observada, del cambio en el objetivo de saldos acumulados y de las sorpresas inflacionarias (la diferencia entre la inflación observada y la esperada). Los resultados de esta ecuación se presentan en el Cuadro 7. Todos los coeficientes resultan significativos y tienen el signo correcto. también se realizaron estimaciones recursivas para el período de diciembre de 1997 a octubre de 2000. En la Gráfica 13 se presentan los resultados de ésta regresión recursiva para el coeficiente asociado a la depreciación cambiaria.

Como es posible observar en la Gráfica 13, de 1998 a 2000, el pass-through se redujo de manera significativa. El efecto de una depreciación de 1 por ciento sobre el cambio en la expectativa de inflación de los siguientes doce meses, disminuyó de un nivel de alrededor de 6 puntos base a menos de un punto base. Es importante notar, sin embargo, que de existir una relación no lineal entre la depreciación cambiaria y la tasa de inflación, ésta podría estar sesgando los resultados que aquí se presentan y podría explicar parte del debilitamiento reciente del passthrough ${ }^{13}$, debido a que durante el período de estimación no se observaron depreciaciones bruscas del tipo de cambio.

\section{Cuadro 7}

\section{Determinantes de los Cambios en las Expectativas de Inflación para los Siguientes 12 Meses}

\begin{tabular}{|c|c|}
\hline Cambio en el "Corto" & $\begin{array}{l}0.0051 \text { *** } \\
(0.0019)\end{array}$ \\
\hline Depreciación Rezagada & $\begin{array}{l}0.0379 * * * \\
(0.0107)\end{array}$ \\
\hline Sorpresas de Inflación & $\begin{array}{l}0.7939 * * * \\
(0.1935)\end{array}$ \\
\hline Precios Administrados y Concertados & $\begin{array}{r}-0.0023 \\
(0.0019)\end{array}$ \\
\hline$\overline{\mathrm{R}}^{2}$ & 0.464 \\
\hline
\end{tabular}

13 Garcés (2000) encuentra evidencia de una relación no lineal entre las fluctuaciones del tipo de cambio y la tasa de inflación para el caso de México. 


\section{Gráfica 13 \\ Comportamiento del Coeficiente de la Depreciación del Tipo de Cambio de la Semana Anterior}

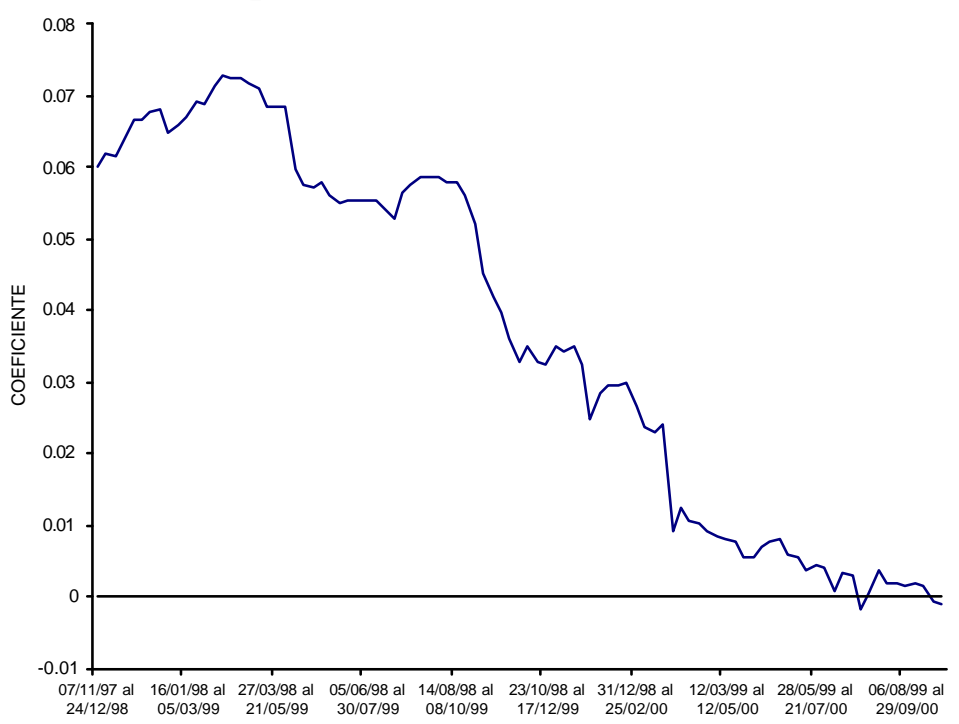

\section{III.4. Resultados de la Instrumentación de la Política Monetaria en México}

En el contexto de la conducción de la política monetaria en México el logro de la meta de inflación es el objetivo primordial de la autoridad monetaria, y ésta actúa cada vez que juzga que las condiciones monetarias determinadas por el mercado son incompatibles con dicho objetivo. Como se señaló, en un ambiente de constantes perturbaciones tanto internas como externas el esquema actual de instrumentación de la política monetaria en México ha resultado eficaz para distribuir el efecto de estas perturbaciones entre el tipo de cambio y la tasa de interés. Sin embargo, bajo este esquema de instrumentación el comportamiento de la tasa de interés está influido también por los ajustes realizados por los agentes en el mercado, lo que significa que las acciones de política monetaria del Banco Central puedan verse contrarrestadas por estos ajustes, limitando su efectividad para lograr la meta de inflación.

Una manera de evaluar la efectividad del esquema de saldos acumulados y de las acciones de política monetaria es a través de la estimación los determinantes del comportamiento de la tasa real de interés. Varios autores han estudiado la regla de política que debe seguirse en el contexto de las economías emergentes, generalizando el análisis de la función de reacción de un Banco Central que determina la tasa de interés en una economía cerrada que busca la estabilización del nivel de precios. Por ejemplo, Svensson (1998) y Ball (2000) desarrollan modelos de una economía abierta 
bajo expectativas racionales, obteniendo que la función de reacción del Banco Central tiene como elementos a la tasa de interés externa y al tipo de cambio real, además de las variables tradicionales como son la brecha del producto y la tasa de inflación actual u observada. A su vez, Corbo (1999) estudia los factores que contribuyen a explicar la conducción de la política monetaria en América Latina.

Para evaluar si el esquema de saldos acumulados en México ha redundado en un comportamiento de la tasa de interés real acorde con el objetivo de reducir la inflación, a continuación, siguiendo las estimaciones realizadas por Ortiz (2000), se estima la función que explica el comportamiento de la tasa de interés real ex-ante. Esto es, una regla de Taylor para la economía mexicana para el período de mayo de 1997 a agosto de 2000. Los determinantes de la tasa de interés real ex-ante que se incluyen en el análisis son: la desviación entre la expectativa de inflación del sector privado y la meta del Banco Central, una medida de la brecha del producto respecto a su nivel potencial, la tasa de depreciación del tipo de cambio observada en el período precedente, y el rendimiento neto de la deuda pública denominada en moneda extranjera.

Los resultados bajo diferentes especificaciones se presentan en el Cuadro 8. En las primeras tres columnas la tasa real considerada se calcula en base a la expectativa de inflación para los siguientes 12 meses. Mientras que para las últimas tres columnas se toma la inflación esperada para el mes, es claro que en este caso se tendrán fluctuaciones estacionales importantes por lo que la tasa real resultante se ajustó para eliminar dicha variabilidad. Además para cada tasa de interés se realizan tres estimaciones, para diferentes períodos. En general se cumple que los coeficientes estimados para la regla de Taylor, tomando la tasa de interés derivada de la inflación para los siguientes 12 meses, son mayores para todas las variables excepto para el rendimiento de los bonos en dólares, que los estimados al utilizar la inflación esperada para el mes.

La columna (1) muestra los resultados obtenidos considerando el período mencionado. Todos los coeficientes tienen los signos esperados, aunque la brecha del producto no resulta estadísticamente significativa. Los resultados de la columna (4) corresponden también al período completo utilizando la segunda estimación descrita para la tasa de interés. En este caso los signos también resultan los esperados, pero sólo la tasa de interés en dólares resulta significativa.

De mayo de 1997 a noviembre de 1998 los mercados financieros internacionales resintieron las perturbaciones provocadas por la crisis de Asia y Rusia. Estos eventos fueron fuente de volatilidad para las economías emergentes, y se tradujeron en incrementos en el rendimiento neto de los bonos colocados en el exterior y en depreciaciones cambiarias considerables. Además, como se 
explicó en la sección II, en 1998 comenzó en México la transición hacia un nuevo esquema de objetivos explícitos de inflación. Con el objeto de captar un posible cambio en los determinantes de la tasa de interés real ex-ante durante este período, tanto debido a factores externos como a una modificación en la función de reacción de la autoridad monetaria, la muestra se dividió en dos subperíodos presentándose los resultados obtenidos del primer subperíodo en las columnas (2) y (5). Como es posible observar en dichas columnas, los únicos determinantes significativos de los cambios en la tasa de interés real ex-ante para el período que va de mayo de 1997 a noviembre de 1998 resultaron ser la depreciación cambiaria del período precedente y el rendimiento de los bonos del gobierno colocados en el exterior.

Por otro lado, para el período de diciembre de 1998 a agosto de 2000, cuando se observó una mayor estabilidad en los mercados financieros internacionales, la importancia relativa de los determinantes de los movimientos en la tasa de interés real se revierte. Como puede observarse, en los resultados que se presentan en la tercera y sexta columnas del Cuadro 8, el coeficiente de las desviaciones de la inflación esperada con respecto a la inflación objetivo aumenta y se vuelve estadísticamente significativo. Lo mismo sucede con el coeficiente de la brecha del producto. En contraste, los coeficientes del rendimiento de los bonos colocados en el exterior y de la depreciación cambiaria se vuelven no-significativos.

\section{Cuadro 8}

Regla de Política Monetaria del Banco de México

\begin{tabular}{|c|c|c|c|c|c|c|}
\hline & \multicolumn{3}{|c|}{$\begin{array}{c}\text { Tasa de interés real } \\
\text { (Expectativa Inflación } 12 \text { meses) }\end{array}$} & \multicolumn{3}{|c|}{$\begin{array}{c}\text { Tasa de interés real } \\
\text { (Expectativa Inflación para el mes) }\end{array}$} \\
\hline & (1) & $(2)$ & (3) & (4) & (5) & (6) \\
\hline Constante & $\begin{array}{l}-10.92 \\
(8.28)\end{array}$ & $\begin{array}{l}-16.12 \\
(15.06)\end{array}$ & $\begin{array}{l}-6.92 \\
(7.65)\end{array}$ & $\begin{array}{c}-16.94 * \\
(9.34)\end{array}$ & $\begin{array}{c}-30.52^{* *} \\
(13.16)\end{array}$ & $\begin{array}{l}-4.24 \\
(6.22)\end{array}$ \\
\hline Inflación Esperada - Inf. O bjetivo & $\begin{array}{c}1.65^{* * *} \\
(0.49)\end{array}$ & $\begin{array}{c}0.72 \\
(0.89)\end{array}$ & $\begin{array}{c}2.80^{* * *} \\
(0.78)\end{array}$ & $\begin{array}{l}0.45 \\
(0.47)\end{array}$ & $\begin{array}{l}-0.59 \\
(0.76)\end{array}$ & $\begin{array}{r}1.21 * * \\
(0.52)\end{array}$ \\
\hline Brecha del Producto & $\begin{array}{c}0.09 \\
(0.18)\end{array}$ & $\begin{array}{l}-0.22 \\
(0.31)\end{array}$ & $\begin{array}{l}0.42^{* *} \\
(0.17)\end{array}$ & $\begin{array}{c}0.04 \\
(0.23)\end{array}$ & $\begin{array}{l}-0.48 \\
(1.24)\end{array}$ & $\begin{array}{l}0.34^{*} \\
(0.17)\end{array}$ \\
\hline Tasa de D epreciación Rezagada & $\begin{array}{c}0.39 * * * \\
(0.16)\end{array}$ & $\begin{array}{c}0.61^{* * *} \\
(0.21)\end{array}$ & $\begin{array}{c}0.08 \\
(0.20)\end{array}$ & $\begin{array}{c}0.17 \\
(0.15)\end{array}$ & $\begin{array}{l}0.36^{*} \\
(0.19)\end{array}$ & $\begin{array}{l}-0.22 \\
(0.25)\end{array}$ \\
\hline $\begin{array}{l}\text { Rendimiento de los Bonos del } \\
\text { Gobierno Colocados en el Exterior }\end{array}$ & $\begin{array}{l}1.51 * * \\
(0.87)\end{array}$ & $\begin{array}{c}2.13 \\
(1.60)\end{array}$ & $\begin{array}{c}0.97 \\
(0.83)\end{array}$ & $\begin{array}{l}2.14^{* *} \\
(0.99)\end{array}$ & $\begin{array}{c}3.62 * * \\
(1.43)\end{array}$ & $\begin{array}{c}0.79 \\
(0.67)\end{array}$ \\
\hline $\mathrm{N}$ & 41 & 19 & 22 & 41 & 19 & 22 \\
\hline$\overline{\mathrm{R}}^{2}$ & 0.63 & 0.68 & 0.68 & 0.44 & 0.64 & 0.36 \\
\hline
\end{tabular}


En consecuencia, es posible concluir que durante el período de mayor estabilidad en los mercados internacionales de capital y de transición hacia un régimen de objetivos de inflación, el comportamiento de las tasas de interés reales fue congruente con la necesidad de abatir las presiones inflacionarias provenientes del mercado interno como secuela de las fluctuaciones de la demanda agregada y de las diferencias entre la inflación esperada y la objetivo.

El análisis presentado en esta sección indica que la instrumentación de la política monetaria en México con base en el objetivo de saldos acumulados y en la aplicación de los "cortos", ha repercutido en un comportamiento de la tasa de interés real acorde con la estabilización del nivel de precios. En un contexto de alta volatilidad externa y de un elevado pass-through, la instrumentación de la política monetaria ha contribuido a absorber las perturbaciones sin recurrir a constantes reversiones frecuentes en el instrumento de política monetaria, lo cual hubiese enviado señales ambiguas a los participantes del mercado. Por otro lado, en el período reciente de mayor estabilidad, el esquema monetario ha redundado en un comportamiento de la tasa de interés dirigido a contrarrestar perturbaciones de demanda agregada y del diferencial entre las expectativas y el objetivo de inflación.

En la siguiente sección se analiza de la efectividad de la política monetaria a través del estudio de los canales de transmisión de dicha política.

\section{Los Canales de Transmisión de la Política Monetaria en México durante el Período 1997-2000.}

\section{IV.1. Descripción del mecanismo de transmisión de la política monetaria.-}

La literatura económica ha revisado ampliamente, tanto desde el punto de vista teórico como empírico, el proceso por el cual la autoridad monetaria puede afectar la tasa de inflación. El Diagrama 1 ilustra los mecanismos, recopilados en esta literatura y resumidos por Mishkin (1995), a través de los cuales la autoridad monetaria afecta la evolución de la tasa de inflación. Mediante sus acciones de política monetaria, la autoridad tiene la posibilidad de influir sobre las tasas de interés de corto plazo y las expectativas de inflación. El Banco Central puede afectar las tasas de interés de manera directa, tal como lo hace en la actualidad un gran número de bancos centrales, o de manera indirecta a través de restricciones cuantitativas como las utilizadas por el Banco de México. Las 
diferencias, ventajas y desventajas de los instrumentos utilizados por algunas autoridades monetarias en el mundo y a través del tiempo se presentaron en la sección III.1.

\section{Diagrama 1}

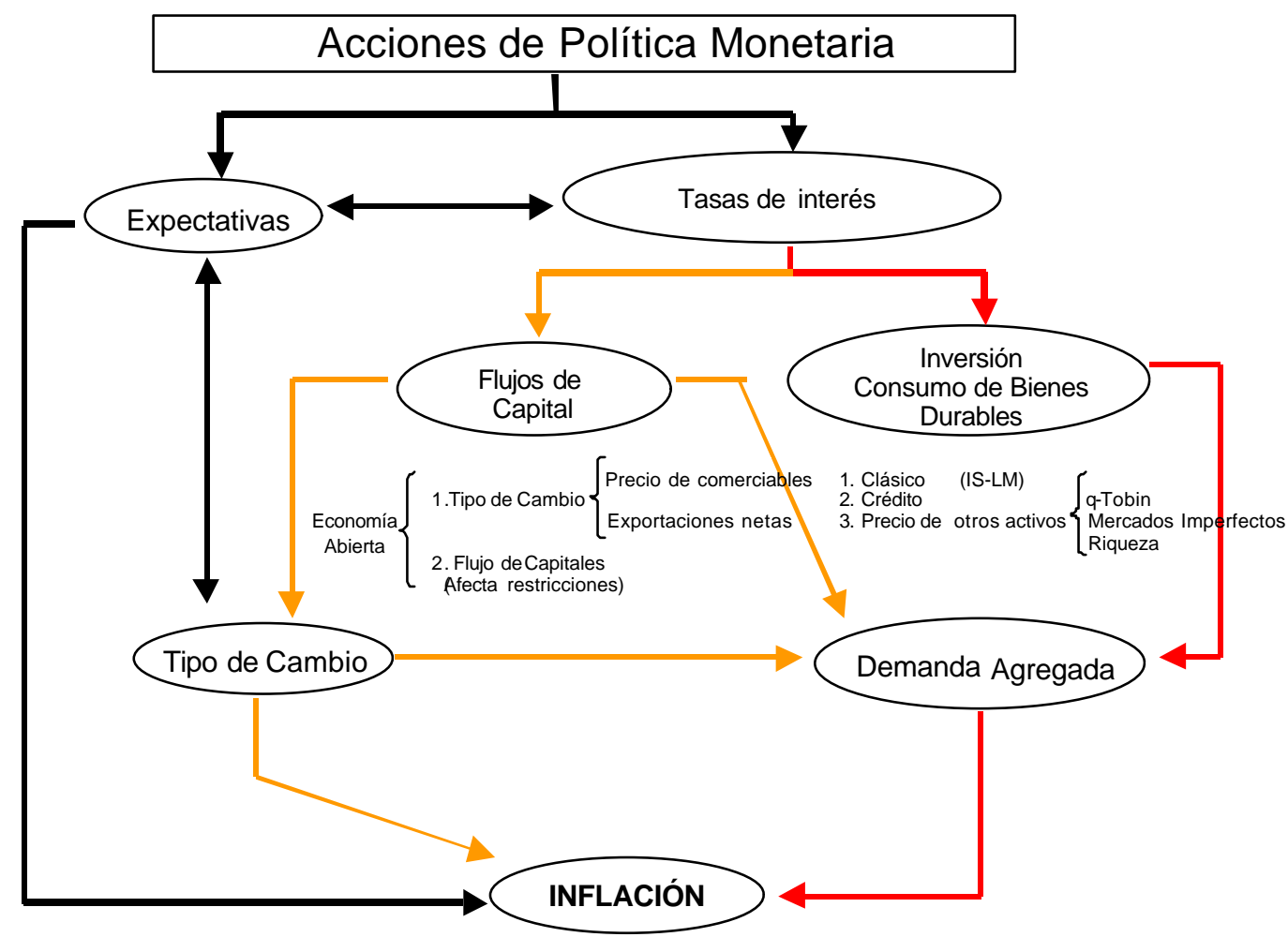

Como se aprecia en el diagrama, la tasa de interés afecta la evolución de las expectativas de inflación, las que a su vez también influyen sobre la determinación de las propias tasas, reforzando el efecto de las acciones tomadas por el Banco Central. A continuación se explica la manera cómo estas variables afectan la demanda agregada y demás variables económicas que inciden sobre en la determinación de precios. Por simplicidad, se describe la transmisión de una política monetaria restrictiva, pero el mecanismo opera de manera inversa ante una política expansiva.

Cuando los anuncios de la autoridad cuentan con plena credibilidad, el Banco Central puede controlar la inflación sin necesidad de afectar de manera significativa a la actividad económica. Esto se debe a que si todos los agentes económicos confíen en los objetivos de la autoridad y toman sus decisiones de fijación de precios con base en éstos, el crecimiento de los precios será igual a la inflación objetivo. En este escenario nunca se presentarían discrepancias entre la inflación esperada y la objetivo y, por ende, no se necesitaría de acciones de la autoridad para inducir un comportamiento de los precios en línea con los objetivos. Por tanto, en estas circunstancias puede lograrse una reducción o un control en la inflación de manera directa con un mínimo costo. Este fenómeno depende en gran medida de la reputación de que goza la autoridad. En general, una 
economía con alta inflación que requiere de un esfuerzo de estabilización, difícilmente cuenta con la credibilidad $^{14}$ necesaria. En estos casos, la expectativa de inflación permanecerá por encima de la inflación objetivo. En consecuencia, por lo que para alcanzar dicho objetivo será necesario inducir una desaceleración de la economía a través de un aumento en las tasas de interés.

El incremento en la tasa real de interés afecta a la inflación por dos principales vías. La primera surge por el impacto sobre el costo de financiamiento, el cual a su vez puede dividirse en tres rubros. En primer lugar, se tiene el canal de demanda agregada. Este es el que se ilustra en el modelo IS-LM tradicional y que indica que un aumento en la tasa de interés de corto plazo se transmite a toda la curva de tasas a plazos, encareciendo el financiamiento e incentivando así una reducción en la inversión y un aumento en el ahorro. Esta caída en la demanda agregada disminuye las presiones sobre los precios y en última instancia la inflación. En segundo lugar, se tiene el llamado canal crediticio, inicialmente enfatizado por Bernanke (1983). Este se sustenta en las imperfecciones del mercado crediticio, las cuales dan lugar a que un aumento en las tasas de interés reduzca la oferta de crédito. En esta literatura se han presentado diversos motivos por los que se produce este efecto ${ }^{15}$. Inclusive se hace una distinción entre el canal de crédito bancario y el del sector financiero más amplio al que se le ha llamado mecanismo financiero-acelerador. El canal del crédito bancario puede explicarse de la siguiente manera. Un aumento en la tasa de interés activa atrae a proyectos más riesgosos, aumentando el costo de vigilancia que realizan los bancos y ocasionando un incremento en el costo de intermediación, el cual se ve reflejado en el diferencial entre la tasa activa y la pasiva. Ello repercute en última instancia en la oferta de crédito, afectando negativamente a la inversión. Para comprobar la existencia de ese canal varios autores han buscado evidencia empírica de si la política monetaria afecta dicho diferencial. También se ha estudiado si al controlar por el nivel de tasas de interés este diferencial contribuye a explicar las variaciones de la inversión. Un efecto similar, el acelerador, se desencadena como consecuencia de una recesión. Así al reducirse la riqueza de los agentes se incrementan los problemas de agencia por lo que se reduce la oferta de crédito y se amplía el diferencial de tasas (Bernanke y Gertler (1989)).

El tercer canal relacionado con el costo del financiamiento surge como resultado de una reducción en los precios del mercado de valores motivada por la subida en la tasa de interés. De acuerdo a la teoría de la inversión de la $q$ de Tobin, cuando el valor de una empresa, aproximado por su valor de mercado, es menor que el costo del capital ocurrirá una desinversión. La presencia

14 Salvo en el modelo de Sargent (1986) la mayoría de los modelos de estabilización requiere de un costo en términos de producto y empleo.

15 La primera formalización de este canal la realizan Bernanke y Blinder (1988), en el cual las reservas bancarias obligatorias jugaban un papel fundamental. 
de información asimétrica en los mercados financieros refuerza este efecto, debido a que en estas circunstancias el acceso de una empresa al financiamiento depende en gran medida de las garantías que pueda ofrecer. Éstas, a su vez, se encuentran determinadas por el valor de la empresa, que en el caso de las emisoras está dado por su valor de mercado. Por ello, al subir las tasas de interés, baja el precio de las acciones y se limita la capacidad de financiamiento de las empresas. Lo anterior redunda en una menor inversión. Adicionalmente, la caída en el mercado de valores implica una contracción de la riqueza de los individuos que invierten en este mercado, quienes reducirán su consumo en respuesta a esta perturbación.

La segunda gran vía al que se hizo referencia, denominada de tipo de cambio, sólo aplica cuando se tiene una economía abierta tanto al comercio de bienes y servicios como a los flujos de capital. Ante un aumento en las tasas de interés, la inversión en bonos denominados en pesos se vuelve más atractiva, por lo que se genera un aumento en el flujo de capitales hacia el país. Bajo un régimen de tipo de cambio flexible dicho flujo conlleva en una apreciación del tipo de cambio. En un país como México, con poco poder en los mercados internacionales, la apreciación se traduce en una reducción en el precio en moneda nacional de los bienes comerciables. Esta disminución en el precio de los bienes comerciables hace más atractiva la producción de bienes no comerciables, por lo que tiene lugar una reasignación de los recursos productivos de los sectores comerciables hacia los no comerciables. Por el lado de la demanda, al hacerse relativamente más caros los bienes no comerciables se reducirá la cantidad demandada de los mismos. Ambos efectos, el de demanda y el de oferta, propician que eventualmente también se registre una reducción en los precios de los bienes no comerciables. Cabe mencionar que un elevado uso de insumos importados puede reforzar aun más dicho efecto.

Adicionalmente, el impacto sobre el flujo de recursos provenientes del exterior puede afectar a la demanda agregada, debido a la existencia de restricciones de liquidez tanto para los consumidores como para las empresas. Este efecto va en dirección opuesta a los descritos en el párrafo anterior. Una mayor entrada de recursos aprecia el tipo de cambio y también incrementa la demanda agregada, llevando por este último canal a una presión alcista sobre los precios, que por motivos de la restricción que impone la competencia internacional sobre el precio de los comerciables, solo se verá reflejada en los bienes no comerciables.

En la siguiente sección se analiza la importancia de los diferentes canales de transmisión de la política monetaria para la economía mexicana. La identificación de la importancia relativa de éstos resulta crucial para la evaluación de la efectividad de la política monetaria. 


\section{IV.2. Estimación de los Canales de Transmisión para la Economía Mexicana.-}

En esta sección, utilizando la técnica de vectores autorregresivos (VAR), se estudian los mecanismos a través de los cuales se ha dado la transmisión de la política monetaria hacia la inflación en la economía mexicana en el período de 1997 a 2000.

A continuación se presenta un modelo simple que incorpora los elementos descritos en la sección anterior que son relevantes para una economía abierta y que se utilizan para determinar las limitaciones que conllevan los supuestos de identificación impuestos al estimar el VAR. La ecuación (1) está dada por una curva de Phillips, que relaciona la inflación observada con la brecha entre el producto observado y el potencial y la brecha del tipo de cambio real con respecto a su nivel de equilibrio. Con el fin de mantener limitado el número de variables en el sistema, sin excluir variables fundamentales en el mecanismo de transmisión de la política monetaria, se considera la tasa de inflación subyacente. De esta manera se evita el problema de tratar de controlar por variaciones en la inflación asociadas a perturbaciones distintas de las especificadas en el modelo, tales como aquéllas que afectan la determinación de los precios de los bienes y servicios públicos, de los productos agrícolas y de los productos básicos que se determinan en mercados internacionales. Es claro que aún así, las fluctuaciones en los precios de los bienes y servicios no incluidos en el cálculo de la inflación subyacente pueden afectarla de manera indirecta y con cierto rezago. Debido a que se encuentra que el tipo de cambio real es estacionario, el tipo de cambio real de equilibrio es constante, por lo que su efecto forma parte del intercepto de la ecuación.

$$
\pi_{t}=\alpha_{0}+\alpha_{1}\left(y-y_{P}\right)_{t}+\alpha_{2}\left(T C R_{t}-\overline{T C R_{t}}\right)+\varepsilon_{t}^{\pi}
$$

La ecuación (2) muestra los determinantes de la brecha entre el ingreso observado y el potencial. Esta brecha depende en primera instancia de la tasa de interés real y del tipo de cambio real. El efecto de estas variables aparece con al menos un mes de rezago, aunque en general se ha encontrado en la literatura que éste es de más de seis meses. El error en esta ecuación puede reflejar perturbaciones tales como alteraciones en la política fiscal, o en la propensión a consumir debido a variaciones en las expectativas del crecimiento económico.

$$
\left(y-y_{P}\right)_{t}=\beta_{0}+\beta_{1} r_{t-i}+\beta_{2} T C R_{t-i}+\varepsilon_{t}^{y}
$$

A pesar de que la política monetaria en México no ha sido instrumentada a través de la determinación directa de las tasas de interés, se puede decir que independientemente del instrumento utilizado por el Banco Central, cualquier cambio en la tasa de interés real tiene efectos sobre la evolución de los determinantes de la inflación y eventualmente sobre el comportamiento de ésta. La ecuación (3) describe el proceso de determinación de la tasa de interés real, mismo que 
puede interpretarse como la función de reacción del mercado y del Banco Central, la cual es similar a la presentada en la sección III. Con el propósito de no adoptar supuestos innecesarios, se incorpora la brecha del producto de manera contemporánea, lo cual implica que la autoridad monetaria cuenta con indicadores adelantados confiables. Al adoptarse esta especificación es posible determinar si en efecto se da esta reacción de manera contemporánea o bien con cierto rezago.

$$
r_{t}=\gamma_{0}+\gamma_{1}\left(y-y_{P}\right)_{t}+\gamma_{2}\left(E(\pi)-\pi_{o b j}\right)+\gamma_{3}\left(T C R_{t}-\overline{T C R}\right)+\varepsilon_{t}^{r}
$$

Es importante notar que la tasa de interés relevante en las ecuaciones (2) y (3) es la real exante, ya que tanto la autoridad monetaria como los inversionistas y consumidores toman sus decisiones con base en esta tasa, debido a que la inflación actual sólo se observa con cierto rezago. Para completar el modelo se requiere una ecuación del tipo de cambio, la cual se puede modelar conforme a la ecuación de paridad de tasas expresada en términos reales. De manera que la devaluación real esperada, en un entorno de flotación, quede determinada por la discrepencia de las tasas reales, ajustada por el riesgo país.

Una aproximación de este modelo puede ser estimada con un VAR, adoptando una descomposición triangular con el siguiente orden: $T C R_{t,}\left(y-y_{p}\right), \pi$ y $r$. En esta especificación no se está considerando el efecto de la brecha entre la inflación esperada y la objetivo. Este supuesto implica que el error identificado como $\varepsilon_{t}^{r}$ incorporará cualquier cambio exógeno de la tasa de interés real que esté motivado por una variación en esta diferencia. Otro supuesto importante es que se impone la restricción de que la tasa de interés afecte al TCR tan sólo con un mes de rezago. Además se incluye el rendimiento de bonos mexicanos denominados en moneda extranjera como variable exógena, para controlar por perturbaciones externas ${ }^{16}$.

Las variables utilizadas en el análisis son las siguientes:

$$
\begin{array}{ll}
T C R=l e+l p^{*}-l p & \text { logaritmo del tipo de cambio real } \\
\left(y-y_{p}\right) & \text { Indice de la producción industrial menos su tendencia }{ }^{17} \\
\pi & \text { Inflación subyacente mensual anualizada }(\%) \\
r=\operatorname{cetes} 28-E(\pi) & \text { Tasa de interés anualizada real ex-ante }(\%) \\
i^{*} & \text { Rendimiento bruto de los bonos UMS26 }(\%)
\end{array}
$$

16 Al incluir el crecimiento del producto en los Estados Unidos como una variables exógena adicional, los resultados no se ven afectados.

17 La tendencia se calculó en base al filtro de Hodrick Prescott. 
La disponibilidad de datos sobre expectativas de inflación limita de manera importante el período para el cual se puede llevar a cabo la estimación, el cual abarca de mayo de 1997 a mayo de 2000. Sin embargo, la ventaja ganada en el poder explicativo del sistema justifica que se utilice dicha variable para el cálculo de la tasa real. Esto se debe a que durante los últimos años ha habido períodos en los que las expectativas de inflación han mostrado un alto error de predicción. Lo anterior ocasiona que los resultados encontrados considerando la tasa real ex-post difieran de manera significativa de los obtenidos al incluir la tasa ex-ante.

La especificación adoptada y el uso de la tasa de interés real ex-ante permiten identificar las perturbaciones a la tasa de interés independientes de otros factores que afectan la oferta de recursos del exterior. Esto se observa al encontrar que de haberse optado por una especificación en la que la tasa de interés precediera al tipo de cambio, aun después de controlar por la tasa de interés externa, el cambio en ambas variables se da en la misma dirección. Esta reacción representa la respuesta a una perturbación en la oferta de flujos de capitales externos y no a un cambio en la tasa de interés cuando dicha oferta se mantiene constante ${ }^{18}$.

La Gráfica 14 muestra las funciones de impulso respuesta resultantes de la estimación del VAR y de los supuestos mencionados. Cada renglón ilustra la reacción de cada una de las variables endógenas a cada uno de las perturbaciones estructurales, presentadas en las columnas.

18 Schwartz y Torres (2000) encuentran efectos similares al considerar innovaciones al "corto". 


\section{Gráfica 14}

\section{Funciones de Impulso Respuesta}
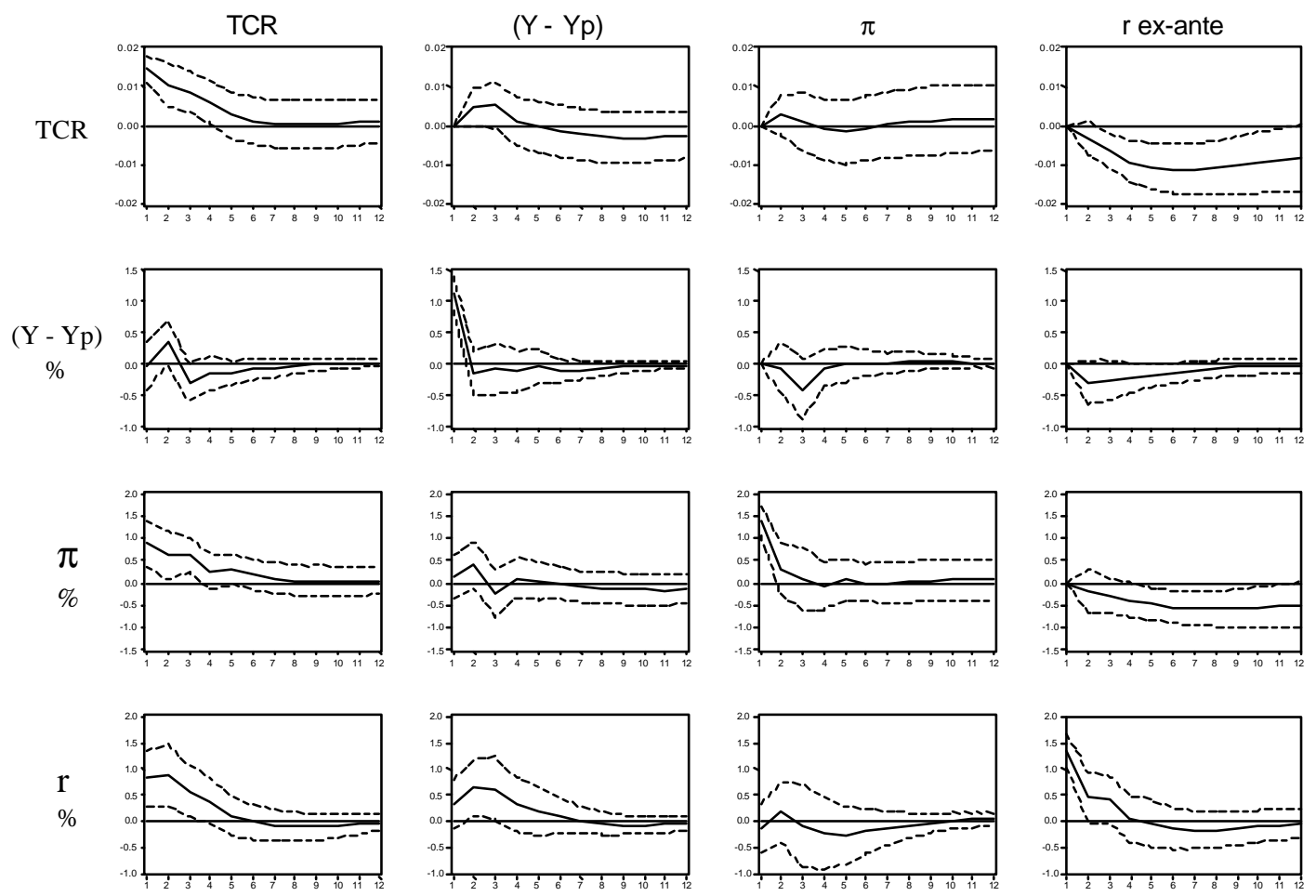

La primera columna de la Gráfica 14 ilustra la dinámica de las variables como resultado de una perturbación de una desviación estándar sobre el tipo de cambio real, equivalente a una devaluación real de 1.4 por ciento. Esta perturbación puede deberse a cualquier factor interno o externo diferente del rendimiento del bono en dólares, el cual se incorporó a la estimación como una variable exógena. El resto de las variables sigue un comportamiento acorde con lo esperado. La brecha del producto aumenta con un mes de rezago y al cabo de tres meses el efecto desaparece. La inflación y la tasa de interés se elevan inmediatamente. La tasa de interés real sube en 0.82 p.p. ante la depreciación real de 1.4 por ciento.

En términos de la velocidad y magnitud del ajuste de precios ante variaciones en el tipo de cambio se encuentra que éste es más lento y de menor magnitud que el obtenido en la sección III.3 y en otros trabajo (por ejemplo Garcés (1999)). Esta diferencia se debe principalmente al período considerado ya que, como señala dicho autor, existe cierta evidencia de que el pass-through del tipo de cambio a precios ha disminuido en los últimos años.

La segunda columna corresponde a una perturbación que afecta la brecha del producto, la cual podría estar asociada, por ejemplo, a una política fiscal expansionista. Ante un aumento en 
dicha brecha el tipo de cambio real, la inflación y la tasa real se incrementan. El aumento en la tasa de interés real puede deberse por un lado, al incremento en la demanda de crédito y, por otro, a una mayor restricción de la política monetaria orientada a reducir el efecto inflacionario de la expansión.

En la tercera columna se aprecia una perturbación sobre la inflación, ante la cual el resto de las variables no responde de manera significativa. Más adelante, al comentarse de la regla monetaria, se ahondará en las posibles interpretaciones relativas a la ausencia de un ajuste de la tasa de interés.

La cuarta columna, presenta la reacción ante un aumento en la tasa de interés real, no explicado por cambios en alguna de las otras variables. Dado que el propósito central de esta sección es estudiar el mecanismo de transmisión de la política monetaria, se presta especial atención al análisis de los resultados ilustrados en esta columna.

Un incremento de 1.4 p.p. en la tasa real ex-ante conlleva una apreciación real que alcanza un máximo de 1 por ciento después de siete meses y desaparece lentamente. La brecha del producto también experimenta una caída al cabo de un mes, en este caso de 0.3 por ciento, respecto del nivel potencial. Este último efecto resulta significativo entre el cuarto y el sexto mes después de la perturbación inicial. La inflación anualizada también se reduce, tanto por el efecto de la apreciación del tipo de cambio real como por la contracción del producto. La reducción de la inflación alcanza su máximo durante el octavo mes y es equivalente a 0.57 p.p.. Al respecto, esta disminución es significativa después de cuatro meses y lo sigue siendo hasta los diez meses.

El último renglón de la gráfica proporciona información acerca de la reacción de la tasa de interés real ante diferentes perturbaciones. Estos resultados indican que la autoridad monetaria y/o el mercado inducen un incremento de las tasas de interés al presentarse presiones inflacionarias ocasionadas por una devaluación (primera columna) o por un incremento en la brecha del producto causada por un aumento de la propensión a consumir, o un relajamiento en la política fiscal u otro factor de demanda (segunda columna). En la tercera columna, se tiene el efecto que tiene un incremento en la inflación, originados por factores diferentes a los dos anteriores, en la tasa de interés real. Como se observa en la gráfica el efecto no es significativo. La trayectoria conjunta de estas variables podría indicar que el mercado y la autoridad identifican a estas perturbaciones como transitorias y probablemente de índole estacional, por lo que resulta óptimo mantener la tasa de interés real constante.

El Cuadro 9 presenta la descomposición de la varianza de largo plazo, esto es la variación atribuible a cada una de las perturbaciones como porcentaje de la varianza total explicada por el modelo. Es importante aclarar que debido a que el rendimiento del bono denominado en dólares se 
incluyó como variable exógena, la varianza explicada es neta del efecto de dicha variable. El área sombreada es la de mayor interés en el sentido de que refleja la importancia relativa que han tenido los movimientos autónomos de la tasa de interés real sobre la evolución de las demás variables del sistema.

\section{Cuadro 9}

\section{Descomposición de la Varianza}

$\%$ Varianza atribuible a perturbaciones sobre:

\begin{tabular}{lcccc}
\hline Variable & TCR & $\left(\mathrm{y}-\mathrm{y}_{\mathrm{p}}\right)$ & $\pi$ & $\mathrm{r}$ \\
\hline \hline TCR & 21 & 6 & 2 & 71 \\
$\left(\mathrm{y}-\mathrm{y}_{\mathrm{p}}\right)$ & 12 & 66 & 8 & 14 \\
$\pi$ & 20 & 6 & 24 & 50 \\
$\mathrm{r}$ & 35 & 19 & 5 & 41 \\
\hline
\end{tabular}

Entre las fuentes internas de variación en la inflación, en el tipo de cambio real y en la brecha del producto, destacan por su importancia los movimientos de la tasa de interés real. Estos últimos explican 14 por ciento de la variación de la brecha del producto y 50 por ciento de la correspondiente a la inflación.

Utilizando los coeficientes estimados se puede determinar cómo se han desviado las tasas de interés de la regla estimada. Ello, al analizar la trayectoria seguida por el error identificado como perturbación a la tasa de interés (Gráfica 15). Por construcción, la media del error es igual a cero, pero llama la atención que durante el último año, a diferencia del resto del período, este error ha sido persistentemente positivo. El comportamiento de dicho error indica que durante este período la tasa de interés real ha estado, en promedio, 1 punto porcentual por encima del valor congruente con la regla estimada. Este resultado es reflejo del endurecimiento de la política monetaria para conseguir mayores reducciones en la inflación. Es importante destacar que este comportamiento se podría incorporar a la regla de política monetaria, haciéndola más general vía la inclusión de la brecha entre la inflación esperada y la inflación objetivo, de modo que el sesgo hacia una postura más restrictiva responda a un aumento en la discrepancia entre la inflación esperada y la objetivo. En la sección III.4 se llevaron a cabo estimaciones estructurales de la función de reacción del Banco de México y, en efecto, se encuentra que esta brecha es importante para la regla monetaria y que inclusive ha cobrado mayor importancia en el último año. En este caso el comportamiento del error indica que para el período mencionado la tasa de interés ha estado únicamente 0.6 p.p. por encima del valor pronosticado por la regla. 


\section{Gráfica 15 \\ Desviaciones de la tasa de interés real ex -ante respecto de la regla monetaria estimada \\ (puntos porcentuales)}

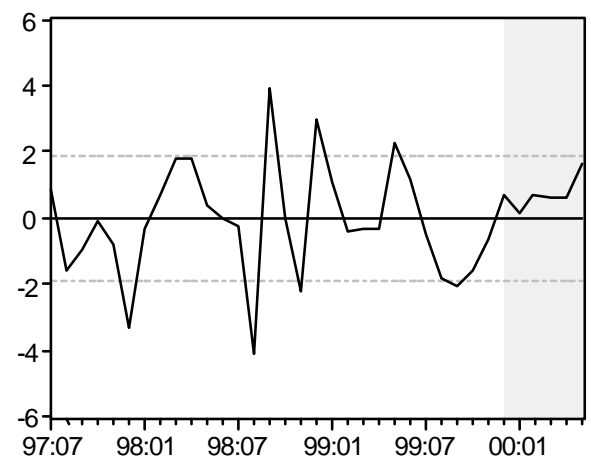

\section{IV.3. Desagregación de I Impacto de una Perturbación en la Tasa de Interés Real.}

La estimación realizada anteriormente indica que un aumento en la tasa de interés real, lleva a una apreciación del tipo de cambio real, induce una menor brecha del producto y genera una reducción de la inflación. Sin embargo, dicha estimación no permite distinguir si la baja en la inflación se debe solamente a la apreciación del tipo de cambio real o si la menor brecha del producto coadyuva a dicho fenómeno. Con este fin, a continuación se realiza una segunda estimación, separando el sector de bienes comerciables y el de los no comerciables. Con esta separación se pretende determinar si la disminución en la inflación a raíz de un aumento en la tasa de interés real se debe exclusivamente al efecto de la apreciación del tipo de cambio sobre los precios de los bienes comerciables.

En segundo lugar, al describir los canales a través de los cuales la política monetaria afecta a la economía se mencionó que el aumento de los flujos de capitales provenientes del exterior, ocasionado por un incremento en las tasas de interés, podría relajar ciertas restricciones de liquidez, creando un efecto expansivo sobre la demanda agregada. En la estimación llevada a cabo con la actividad económica agregada, realizada en la sección anterior, no se puede determinar si este efecto en verdad existe. Sin embargo, en el caso de que estuviera presente, se encontró que es contrarrestado por el impacto recesivo de la tasa de interés más elevada. Al analizar por separado a la inflación de los bienes no comerciables es posible determinar si el incremento en la demanda por este tipo de bienes que se podría dar por dicho efecto es superior al efecto recesivo mencionado. De esta manera se puede establecer ver si una política restrictiva conlleva a una reducción de precios, no sólo por su impacto sobre el tipo de cambio nominal sino además por su incidencia negativa sobre la demanda agregada. 
Para este ejercicio se utilizó como indicador de la inflación de bienes comerciables, la del índice de precios subyacente de mercancías y para la correspondiente a los no comerciables la del índice subyacente de servicios. Desafortunadamente, para el sector no comerciable no se cuenta con indicadores mensuales confiables de la brecha del producto. Debido a esta limitación, no se incluyó la brecha del producto sectorial en las estimaciones. Para poder comparar los resultados, también se excluyó esta variable para el caso de los comerciables.

Se estimó un VAR para cada sector, similar al presentado en la sección anterior, incluyendo las siguientes variables: $T C R, \pi_{i}$ y $r$, en ese orden y donde $i=c o m$ o nocom según el caso. Debido a que la metodología de identificación es la misma a la descrita anteriormente, la interpretación de las perturbaciones descrita también es aplicable.

La Gráfica 16 muestra las funciones de impulso respuesta de la inflación en ambos sectores ante una perturbación que afecta al tipo de cambio ${ }^{19}$. Como es de esperarse, el efecto del tipo de cambio sobre la inflación de los bienes comerciables es inmediato. Una depreciación de 1 por ciento ocasiona un incremento en la inflación anualizada de 0.83 p.p.. En el caso de los no-comerciables el efecto es muy pequeño y no-significativo.

\section{Gráfica 16 \\ Función de Impulso Respuesta ante un perturbación al TCR}

Sector Comerciable (mercancías) Sector No Comerciable (Servicios)
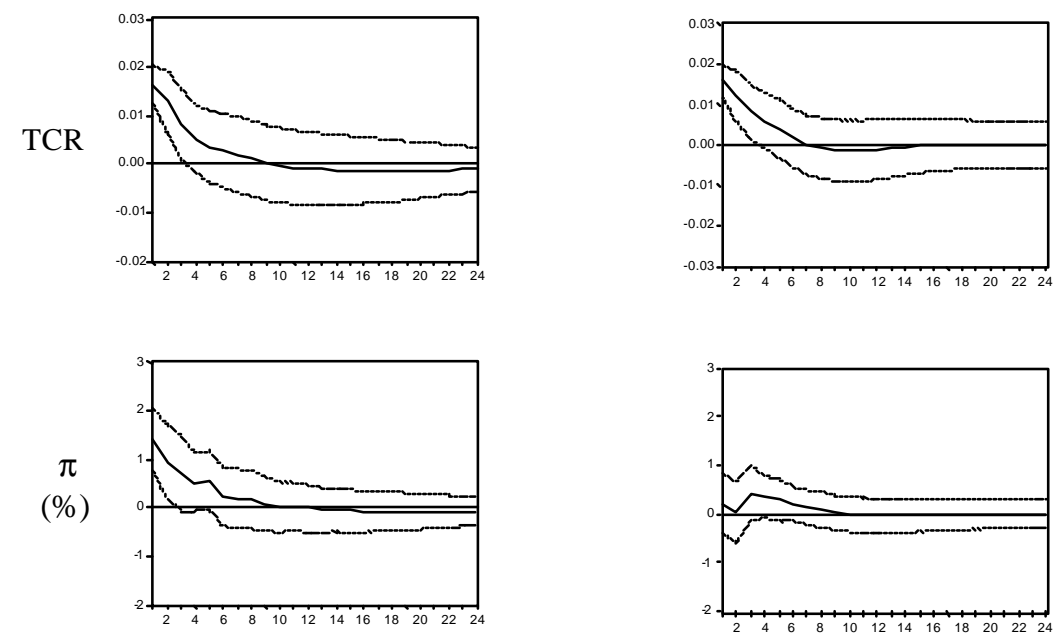

La Gráfica 17 muestra las funciones de impulso-respuesta ante una perturbación sobre las tasas de interés reales. En ambos sectores ocurre una caída en la inflación, aunque de acuerdo a lo

19 No se incluye la gráfica de impulso-respuesta de la tasa de interés por motivos de espacio y debido a que ésta es muy similar a la presentada en la estimación de la economía agregada. 
esperado, el efecto es más rápido y es mayor magnitud en el sector comerciable. Estos resultados indican que el incremento en la demanda como respuesta al mayor financiamiento, es relativamente poco importante en comparación con el efecto de la apreciación y de la contracción ocasionada por el impacto directo de la tasa de interés. Además, a la vez de lo señalado demostrado en la Gráfica 16, la depreciación del tipo de cambio tiene un efecto pequeño y no significativo sobre la inflación de los bienes no comerciables. La caída de la inflación de dichos bienes asociada al aumento de la tasa de interés real se explica por las repercusiones de la contracción de la brecha del producto y no por la apreciación cambiaria.

\section{Gráfica 17}

Funciones de Impulso-Respuesta ante una Perturbación de la Tasa de Interés Real Sector Comerciable (mercancías) Sector No Comerciable (Servicios)
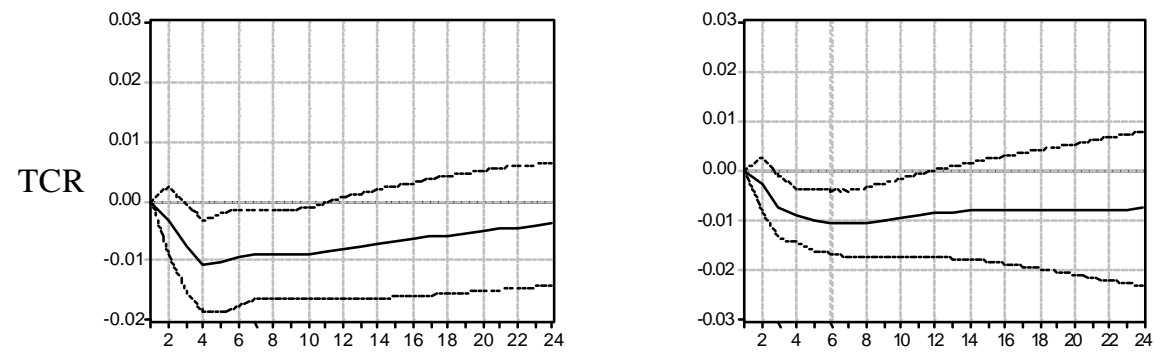

$\pi$

$(\%)$
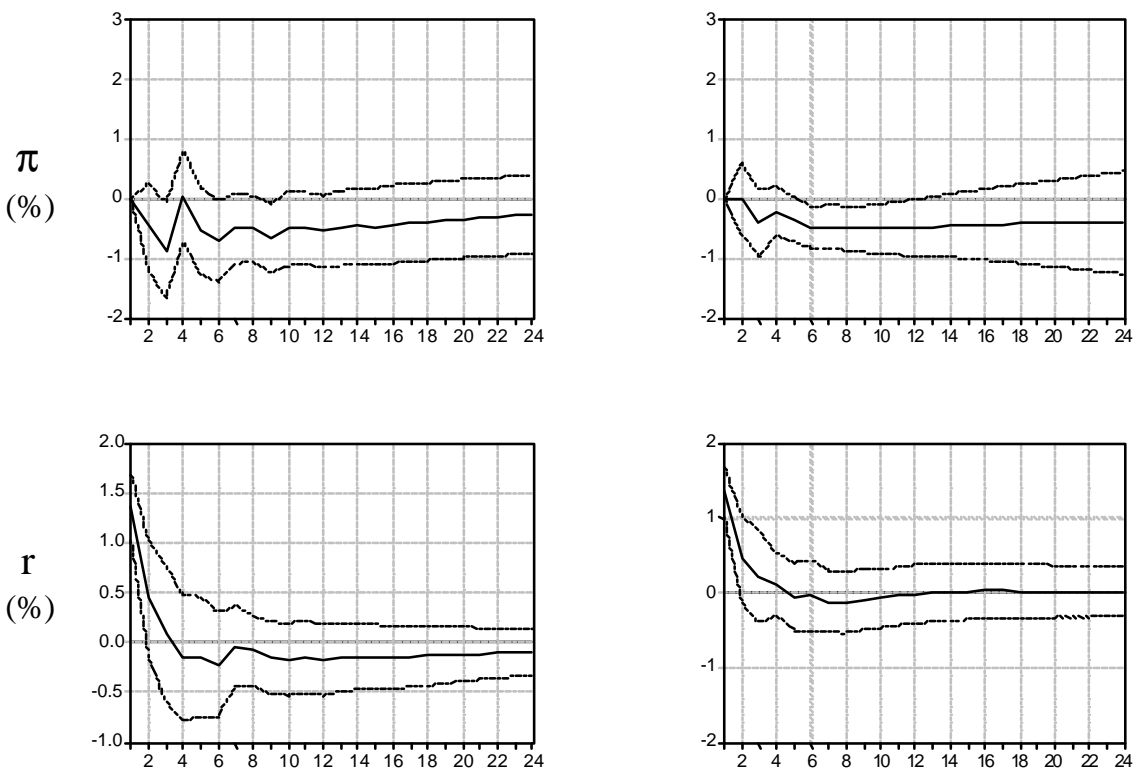

La descomposición de la varianza de la inflación presentada en el Cuadro 10, muestra que aun en el sector de los no-comerciables las perturbaciones a la tasa de interés real son muy importantes en la determinación de la inflación, explicando 44 por ciento de la varianza de ésta. 
Para el caso de los comerciables, la importancia de dichas perturbaciones es menor debido a que en este caso el tipo de cambio juega un papel fundamental. Sin embargo, aun así explican 41 por ciento de la varianza. En segundo lugar, destaca el fenómeno de que las perturbaciones al tipo de cambio real explican un porcentaje casi insignificante de la varianza de la inflación de los bienes no comerciables. Estos resultados sugieren que el canal tradicional de transmisión de la política monetaria sí ha operado en la economía mexicana en los últimos cuatro años.

Cuadro 10

Descomposición de la Varianza

$\%$ Varianza atribuible a perturbaciones sobre:

\begin{tabular}{lrrr}
\hline Variable & TCR & $\pi$ & r \\
\hline \hline Inf. Comerciables & 34 & 24 & 41 \\
Inf. No Comerciables & 6 & 51 & 44 \\
\hline
\end{tabular}

\section{IV.4. Importancia del Canal de Crédito}

Tal como se describió en la primera sección, las imperfecciones en los mercados financieros tienden a amplificar el efecto de la política monetaria. Esto es, las particularidades del crédito bancario, a diferencia, por ejemplo, del papel comercial implican que un aumento en la tasa de interés da lugar a una disminución en la oferta de este tipo de crédito. Esta menor oferta se reflejará no sólo en la contracción del crédito otorgado sino también en una ampliación del diferencial entre la tasa activa y la pasiva ${ }^{20}$.

Existen algunos estudios que estiman la importancia de este canal para la economía mexicana (Copelman y Werner (1995) y Hernández (1999)). Sin embargo, aún no se cuenta con evidencia para el período a partir de la crisis de 1995. Este análisis resulta particularmente importante debido a que de 1995 a la fecha el crédito bancario en México ha sido sumamente escaso, por lo que a priori es difícil pensar que este canal ha sido importante. Por otro lado, se ha encontrado que el financiamiento no se ha obtenido a través del mercado de bonos sino del mercado externo y de otras fuentes no bancarias (crédito de proveedores). Estos mecanismos crediticios alternativos, al igual que el crédito bancario, están sujetos a graves problemas de información imperfecta, lo cual puede dar lugar a mecanismos similares al canal de crédito tradicional.

En este apartado se analiza la hipótesis anterior llevando a cabo dos estimaciones alternativas. La primera consiste en determinar si la tasa de interés, como reflejo de una restricción monetaria, ha tenido una repercusión significativa sobre el diferencial de tasas activa-pasiva y si

20 Kashyap et al (1993), desarrollan un modelo teórico donde derivan este resultado. 
éste a su vez ha afectado a la actividad económica. La segunda consiste en tomar información del crédito de proveedores por empresa para estimar el efecto que la tasa de interés tiene sobre éste.

\section{Política Monetaria, Diferencial de Tasas y Actividad Económica.-}

Como un primer paso se estimó una regresión por MCO para explicar el comportamiento del diferencial de $\operatorname{tasas}^{21}$, incluyendo como variables explicativas al rezago del diferencial, la devaluación nominal, la tasa de interés de bonos de México denominados en dólares y la tasa de interés real ex-ante en pesos. Posteriormente, se estimó el impacto de este diferencial sobre la actividad económica. Este segundo paso resulta fundamental debido al limitado papel que ha jugado el crédito bancario como fuente de financiamiento. Lo anterior podría ocasionar que, aun cuando se registrara una ampliación significativa del diferencial de tasas este último no tuviera una repercusión importante sobre la economía. La primera columna del Cuadro 11 presenta los resultados de las estimaciones asociadas al primer paso y las últimas dos las correspondientes al segundo paso.

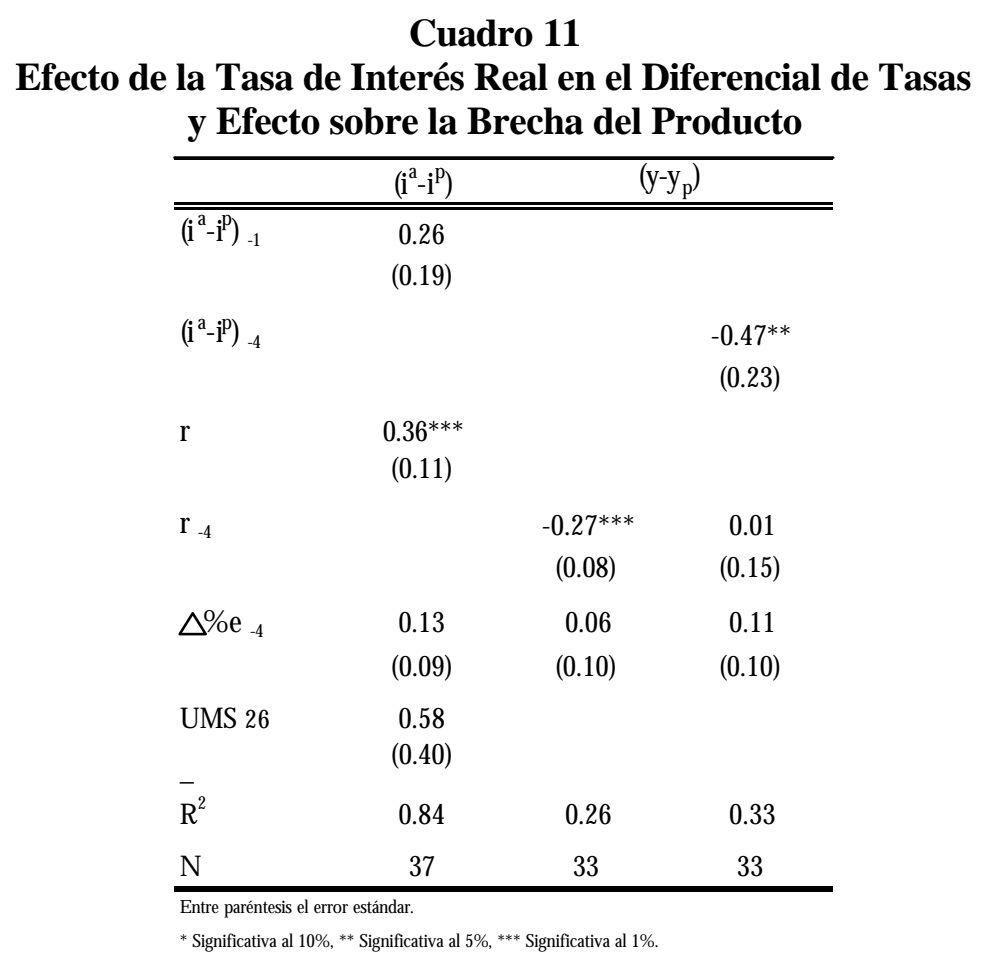

21 El diferencial de tasas de interés es igual a la tasa activa, obtenida de información proporcionada por empresas usuarias de crédito distribuidas en la República Mexicana, menos el CPP. 
$\mathrm{Al}$ estimar los determinantes del diferencial de tasas (primera columna) se obtiene que la tasa real resulta positiva y sumamente significativa; además, la magnitud del efecto resulta bastante grande.

Las estimaciones implican que un aumento en la tasa de interés real de un punto porcentual está asociado con un incremento contemporáneo en el diferencial de 0.36 p.p. y un efecto de largo plazo de 0.49 p.p.. La segunda columna del cuadro muestra que la tasa de interés real es un determinante importante de la brecha del producto, siempre que no se controle por el diferencial. Este efecto resulta negativo y significativo, aun si se controla por la depreciación nominal, e implica que un aumento de 1 p.p. en dicha tasa lleva a una caída del producto, después de cuatro meses, de 0.27 por ciento por debajo de su nivel potencial. Una vez que se incorpora el diferencial de tasas (tercera columna), éste resulta significativo y la tasa real pierde su significancia. Los resultados indican que un aumento en el diferencial de 1 p.p. ocasiona, después de cuatro meses, una disminución de la brecha de 0.47 por ciento del producto potencial. Estos resultados se mantienen después de controlar por diferentes rezagos de la tasa de interés externa.

\section{Tasa de Interés y Crédito de Proveedores.-}

Para este análisis se utilizó información trimestral, para el período de 1996 a 1999, de las empresas no-financieras que cotizan en la Bolsa Mexicana de Valores. El número total de empresas consideradas fue 231. Como indicadores del financiamiento vía proveedores se consideraron los siguientes conceptos: clientes y documentos por cobrar (que reflejan el crédito que estas empresas otorgan) y créditos de proveedores (que reflejan las deudas de las empresas con éstos). Debido a que ambos conceptos constituyen un acervo, se tomaron alternativamente primeras diferencias y tasas de crecimiento como variables endógenas ${ }^{22}$. Para controlar por la situación económica se utilizaron como variables explicativas diferentes transformaciones de las ventas netas ${ }^{23}$. Además, se la tasa de interés real contemporánea y rezagada. Las estimaciones se realizaron mediante la técnica de efectos fijos para datos de panel y se presentan en las primeras dos columnas del Cuadro 12.

22 Por razones de espacio y debido a que los resultados no cambian significativamente, en el cuadro sólo se incluyen las estimaciones con las tasas de crecimiento de las variables endógenas.

23 También se utilizó el crecimiento del PIB, pero debido a que los resultados fueron muy similares no se incluyeron en el cuadro 12. 
Cuadro 12

Efecto de las Tasas de Interés sobre el Crédito de Proveedores

\begin{tabular}{|c|c|c|c|c|}
\hline & $\begin{array}{c}\text { Cuentas por } \\
\text { Cobrar }\end{array}$ & Proveedores & $\begin{array}{c}\text { Cuentas por } \\
\text { Cobrar }\end{array}$ & Proveedores \\
\hline & \multicolumn{2}{|c|}{ 1996-1999 } & \multicolumn{2}{|c|}{ 1989-1994 } \\
\hline$r$ & $\begin{array}{l}0.01^{* *} \\
(0.006)\end{array}$ & $\begin{array}{l}0.03 * * * \\
(0.007)\end{array}$ & $\begin{array}{c}-0.14 \\
(0.356)\end{array}$ & $\begin{array}{c}0.35 \\
(0.442)\end{array}$ \\
\hline $\mathrm{r}_{-1}$ & $\begin{array}{c}-0.02^{* *} \\
(0.006)\end{array}$ & $\begin{array}{c}-0.04 * * * \\
(0.007)\end{array}$ & $\begin{array}{c}0.11 \\
(0.331)\end{array}$ & $\begin{array}{c}0.12 \\
(1796)\end{array}$ \\
\hline Ventas & $\begin{array}{c}-6.22 \mathrm{e}-10 \\
(0.000)\end{array}$ & $\begin{array}{r}-3.0 \mathrm{e}-09 \\
(0.000)\end{array}$ & $\begin{array}{c}0.000 \\
(0.000)\end{array}$ & $\begin{array}{c}0.0004^{* * *} \\
(0.000)\end{array}$ \\
\hline $\mathrm{N}$ & 2095 & 2064 & 4455 & 4430 \\
\hline$\overline{\mathrm{R}}^{2}$ & 0.58 & 0.04 & 0.30 & -0.03 \\
\hline
\end{tabular}

La primera columna del cuadro muestra los resultados tomando las cuentas por cobrar. Se encuentra un efecto contemporáneo positivo de la tasa de interés, y negativo al tomarse un trimestre de rezago. El efecto positivo inicial, común en este tipo de estimaciones, se debe a que ante una subida en las tasas, el pago de los créditos atrasados disminuye. De manera que, en un principio, este efecto domina al de la contracción en créditos nuevos. Sólo después de tres meses se obtiene que este último efecto se vuelve más importante. El efecto neto de un aumento de 1 p.p. en la tasa de interés es una reducción de 0.6 p.p. en la tasa de crecimiento de las cuentas por cobrar.

La segunda columna muestra la misma especificación pero tomando el crédito de proveedores como variable endógena. Se obtuvieron resultados que también confirman la hipótesis de que el crédito de proveedores no es inmune a cambios en la postura de la política monetaria. En este caso el efecto neto de dicho cambio en la tasa de interés es de 1 p.p. sobre el crecimiento de las deudas con proveedores.

En las últimas columnas del cuadro se presentan estimaciones similares para el período precrisis, de 1989 a 1994. Ello, con el fin de determinar si el crédito de proveedores seguía el mismo patrón cuando el crédito bancario experimentaba una fuerte expansión. Esta comparación es importante ya que en la escasa literatura que analiza el efecto que tienen las tasas de interés y, en particular, los cambios en la política monetaria, sobre el crédito de proveedores se encuentra que este último muestra un comportamiento opuesto al del crédito bancario. Lo anterior implica que el 
primero es un sustituto imperfecto del segundo. Al encontrarse que este resultado no es aplicable para México durante el período de 1996 a 1999, surge la duda si ello se debe a que en general el crédito de proveedores es un complemento del crédito bancario o bien a la escasez de este tipo de crédito durante el período estudiado. De acuerdo a lo mostrado en el cuadro los resultados son muy diferentes para el período anterior a la crisis (1989-1994). En este caso no se encuentra un efecto significativo de la tasa de interés sobre el crédito de proveedores. Esto refleja que antes de la crisis dicho crédito respondía a factores distintos de las condiciones agregadas de la economía, como lo son el flujo de efectivo o las ventas netas que ahora resultan significativos para la segunda especificación.

Si bien la evidencia confirma que la tasa de interés real, sí ha afectado negativamente la cantidad de crédito en la economía, es cuestionable la conclusión de que este efecto es atribuible por completo al canal de crédito. Un análisis más detallado, el cual escapa a los objetivos de este trabajo, podría contribuir de manera importante a resolver este dilema. Sin embargo, ambos casos indican que un aumento en la tasa de interés implica una caída en el crédito ya sea que éste se de en forma directa o como resultado de una contracción de la demanda agregada. Lo relevante es que en última instancia el canal de la tasa de interés, independientemente del tipo de cambio, se ha mantenido presente en la economía mexicana a pesar del limitado crédito bancario.

\section{Conclusiones}

En este trabajo se analiza la instrumentación de la política monetaria en México. En primer lugar, se describió la evolución del marco de política monetaria en México a partir de 1995. Posteriormente, se examinaron los mecanismos de operación y la respuesta de la autoridad ante distintas perturbaciones que afectan la evolución de los precios y los efectos de las medidas adoptadas sobre la actividad económica y en última instancia sobre la inflación.

La crisis cambiaria y financiera que tuvo lugar a finales de 1994 y durante 1995 obligó a las autoridades mexicanas a adoptar un régimen cambiario de libre flotación. Por tanto, se abandonó el uso del tipo de cambio como ancla nominal de la economía. En respuesta a las críticas por la falta de transparencia y a la insuficiente diseminación de información, y a la necesidad de establecer un ancla nominal visible y estricta, en 1995 se avanzó un objetivo de crecimiento anual del crédito interno neto. Además, a consecuencia de la gran incertidumbre respecto de la evolución de la economía mexicana, en ese entonces se consideró extremadamente riesgoso utilizar como instrumento de política monetaria la fijación de una tasa de interés de corto plazo. Así, con el fin de 
instrumentar un esquema operativo bajo el cual tanto el tipo de cambio como las tasas de interés fuesen determinadas libremente, el Banco de México estableció el "encaje promedio cero" y comenzó a utilizar el objetivo de saldos acumulados como instrumento de política monetaria.

A partir de 1998, el esquema de política monetaria inició una transición gradual hacia un esquema de objetivos explícitos de inflación. En consecuencia se desenfatizó la evolución de la base monetaria, en tanto que las metas de inflación de corto y mediano plazo adquirieron mayor relevancia. A la vez, las acciones discrecionales de política monetaria se orientaron principalmente a la consecución de los objetivos de inflación de corto y mediano plazo.

La relevancia del estudio radica en su contribución a despejar algunas dudas referentes a la acción del Banco de México en cuanto a lo siguiente:

1. La conveniencia de utilizar un instrumento de restricción cuantitativa en un entorno en el cual la mayoría de los países ha adoptado objetivos de tasas de interés.

2. La eficacia de la política monetaria, en términos generales, en una economía abierta y en la que el financiamiento bancario interno ha sido muy limitado.

Con relación al primer punto, se encontró que si bien el "corto" conlleva mayor incertidumbre en lo que respecta a su efecto sobre las tasas de interés, que la asociada a un esquema de objetivo de tasas, este instrumento ha resultado muy eficaz en cuanto a la distribución de perturbaciones externas entre el tipo de cambio y las tasas de interés. Esta ventaja es de suma importancia en una economía como la mexicana, que está sujeta a una gran volatilidad y a un elevado pass-through de variaciones en el tipo de cambio a precios. El "corto" ha contribuido de manera significativa al proceso de desinflación, especialmente a partir de 1998, cuando se ha visto que la tasa de interés real ex-ante ha reaccionado de manera expedita a las desviaciones de la inflación esperada con respecto a la objetivo.

Por lo que respecta a la efectividad de la política monetaria, los resultados de este trabajo indican que además del canal del tipo de cambio, los canales que afectan la inflación vía el costo de financiamiento han estado operando en la economía mexicana durante el período de 1997 a la fecha.

Mediante la estimación de VARs se llegó a la conclusión de que este efecto ha sido particularmente importante. En primer término, se obtuvo que un incremento autónomo en la tasa de interés real ex-ante, afecta negativamente a la brecha del producto. Un incremento de 1 p.p. de dicha tasa lleva, después de un mes, a una caída del producto de 0.2 por ciento respecto de su nivel 
potencial. Este efecto resulta significativo entre el cuarto y el sexto mes después de la perturbación inicial.

Al analizarse por separado a los bienes comerciables y a los no comerciables se observó que el tipo de cambio por sí sólo no ha tenido un efecto significativo sobre los precios de estos últimos. En contraste, incrementos autónomos en la tasa de interés sí han logrado un efecto negativo y significativo sobre dicha variable. Ambos resultados sugieren que el canal de la tasa de interés, más allá de su efecto sobre el tipo de cambio, ha incidido de manera negativa sobre la demanda agregada y en última instancia sobre el nivel de precios.

Un canal adicional a través del cual ha operado la política monetaria ha sido el de las condiciones crediticias. Incrementos en las tasas de interés reales se han traducido en mayores costos de intermediación, medidos como el diferencial entre las tasas de interés activas y las pasivas. Dichos costos, a su vez, han redundado en una reducción en la brecha del producto. Un incremento de 1 p.p. en la tasa real ex -ante ocasiona, en promedio, un incremento inmediato, del aludido diferencial de 0.36 p.p. y en el largo plazo de 0.49 p.p.. Al cabo de cuatro meses se observa una caída del producto de 0.23 por ciento respecto de su nivel potencial. Además, se encontró que los aumentos en la tasa real ex -ante han afectado negativamente al crédito de proveedores. En promedio, un incremento de 1 p.p. en dicha tasa real ocasiona inicialmente un alza y al cabo de tres meses una caída, siendo el efecto neto una reducción de 0.6 p.p. en la tasa de crecimiento de las cuentas por cobrar. 


\section{Referencias}

Ball, Lawrence (2000). "Policy Rules and External Shocks", NBER Working Paper No. W7910, septiembre.

Bernanke, Ben (1983).'Nonmonetary Effects of the Financial Crisis in the Propagation of the Great Depression”, American Economic Review 73, junio, pp. 257-276.

Bernanke, Ben y Alan Blinder (1988). "Credit, Money and Aggregate Demand", American Economic Review, mayo, pp. 435-439.

Bernanke, Ben y Mark Gertler (1989). “Agency Costs, Net Worth, and Business Fluctuations." American Economic Review, 79, No. 1, marzo, pp 14-31.

Conesa, Andrés (1998). "Pass-Through del Tipo de Cambio y del Salario: Teoría y Evidencia para la Industria Manufacturera en México”, Banco de México, Documento de Investigación No. 9803.

Copelman, Martina y Alejandro Werner (1995). "The Monetary Transmission Mechanism in Mexico", Board of Governor of the Federal Reserve System, International Finance Discussion Papers No. 521, septiembre.

Corbo, Vittorio, Andrés Elberg, José Tessada (1999). "Monetary Policy in Latin America:

Underpinnings and Procedures", Cuadernos de Economía, Año 36, No. 109, 897-927.

Cukierman, Alex (1991). "Why Does the Fed Smooth Interest Rates?", en Michael T. Belognia, ed. Monetary Policy on the $75^{\text {th }}$ Aniversary of the Federal Reserve System, 111-147.

De Brower, Gordon y Neil R. Ericsson (1998). "Modelling Inflation in Australia", Journal of Business and Economic Statistics, octubre, vol.16, No. 4.

Banco de México, Exposición sobre la Política Monetaria para el lapso del $1^{\circ}$ de enero de 1995 al 31 de enero de 1995, pp. 53-54.

Banco de México, Informe Anual de 1997, Anexo 4.

Banco de México, Boletín de Prensa No. 139, noviembre 30, 1998.

Garcés, Daniel (1999). "Determinación del Nivel de Precios y la Dinámica Inflacionaria en México”, Banco de México, Documento de Investigación No. 9907.

Garcés, Daniel (2000). "Cambios de Régimen en la Paridad del Poder de Compra y la Inflación en México", mimeo. 
Hernández, Alfredo (1999). “Afecta la Política Monetaria a los Agregados de Crédito?”, Gaceta de Economía, ITAM, No. 9, pp. 131-158.

Kashyap, Anil, Jeremy Stein y David W. Wilcox (1993). "Monetary Policy and Credit Conditions: Evidence from the Composition of External Finance", American Economic Review, marzo, pp. 7898.

Mishkin, Frederic (1995). "Symposium on the Monetary Transmission Mechanism", Journal of Economic Perpsectives, Vol. 9, No. 4, pp. 3-10.

Ortiz, Guillermo(2000). "How Should Monetary Policy Makers React to the New Challenges of Global Economic Integration: The Case of Mexico", prepared for the symposium "Global Economic Integration: Opportunities and Challenges", sponsored by the Kansas City Fed, Jackson Hole Wyoming.

Sack, Brian (1998). "Does the Fed Act Gradually? A VAR Analysis", Board of Governors of the Federal Reserve System, April.

Sargent, Thomas (1986). Rational Expectations and Inflation. New York: Harper and Row.

Svensson, Lars E. O. (1998). “Open Economy Inflation Targeting”, National Bureau of Economic Research, Working Paper 654, May.

Svensson, Lars E. O. (1999). "Inflation Targeting as a Monetary Policy Rule”, Journal of Monetary Economics 43, 607-654.

Schwartz, Moisés J. y Alberto Torres (2000). "Expectativas de Inflación, Riesgo País y Política Monetaria en México", mimeo.

Walsh, C. E., (1998). Monetary Theory and Policy, MIT Press, Cambridge MA. 